\title{
Transparent and Colorless Dye-Sensitized Solar Cells Exceeding 75\% Average Visible Transmittance
}

\author{
Waad Naim, Vittoria Novelli, Ilias Nikolinakos, Nadia Barbero, Iva Dzeba, Fionnuala Grifoni, \\ Yameng Ren, Thomas Alnasser, Amalia Velardo, Raffaele Borrelli, Stefan Haacke, Shaik M. Zakeeruddin, \\ Michael Graetzel, Claudia Barolo, and Frédéric Sauvage*
}

Cite This: JACS Au 2021, 1, 409-426

Read Online

ACCESS | Lلll Metrics \& More | 稩 Article Recommendations | S1 Supporting Information

ABSTRACT: Most photovoltaic (PV) technologies are opaque to maximize visible light absorption. However, see-through solar cells open additional perspectives for PV integration. Looking beyond maximizing visible light harvesting, this work considers the human eye photopic response to optimize a selective near-infrared sensitizer based on a polymethine cyanine structure (VG20-C $_{x}$ ) to render dye-sensitized solar cells (DSSCs) fully transparent and colorless. This peculiarity was achieved by conferring to the dye the ability to strongly and sharply absorb beyond $800 \mathrm{~nm}\left(\mathrm{~S}_{0}-\mathrm{S}_{1}\right.$ transition) while rejecting the upper $S_{0}-S_{n}$ contributions far in the blue where the human retina is poorly sensitive. When associated with an aggregation-free anatase

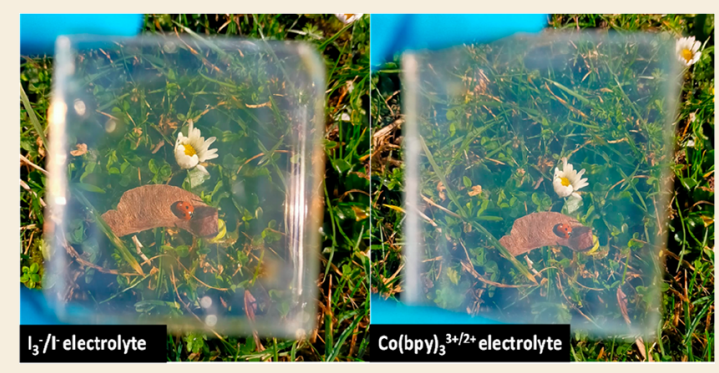
$\mathrm{TiO}_{2}$ photoanode, the selective NIR-DSSC can display $3.1 \%$ power conversion efficiency, up to $76 \%$ average visible transmittance (AVT), a value approaching the $78 \%$ AVT value of a standard double glazing window while reaching a color rendering index (CRI) of $92.1 \%$. The ultrafast and fast charge transfer processes are herein discussed, clarifying the different relaxation channels from the dye monomer excited states and highlighting the limiting steps to provide future directions to enhance the performances of this nonintrusive NIR-DSSC technology.

KEYWORDS: transparent photovoltaic (TPV), dye-sensitized solar cells (DSSC), near-infrared sensitizers, cyanine dyes, time-resolved spectroscopies, high color rendering index TPV

\section{INTRODUCTION}

Energy conversion from sunlight is a sustainable approach to solve long-term energy production, which is compatible with current and future energy needs. Photovoltaic (PV) modules are mostly based on silicon $\mathrm{p}-\mathrm{n}$ junctions and installed on rooftops and in solar farms, representing ca. $4 \%$ of the energy production in Europe. ${ }^{1}$ These two segments were specifically tailored in accordance with the strength of silicon PV technology. However, there are still plenty of opportunities to explore for reaching total independence from fossil fuels and nuclear energy. This is the case of see-through solar technologies, an old concept developed more than 30 years ago, which offers new integration possibilities such as buildingintegrated (BI) and automotive-integrated (AI) PV, electronic displays, autonomously powered electronic-glazing, etc.

The theoretical limit of power conversion efficiency (PCE) for a single junction NIR-selective transparent photovoltaic (TPV) technology with an average visible transmittance (AVT) of $100 \%$ is $20.5 \% .^{2}$ In practice, only $10.8 \%$ can be expected after considering all optical losses. For the same AVT, the PCE is theoretically lower for nonselective broadband absorbing cells. Hence, selective TPV, i.e. selective conversion of either the UV or NIR part of the solar spectrum, represents an important stake for the advancement of such TPV technologies.

Two main approaches have been proposed to reach semi- to transparent PVs: (i) spatially segmented PV or broadband absorbing thin film opaque absorbers such as Si, CIGS, or perovskite solar cells ${ }^{3-11}$ and (ii) wavelength selective thin film PVs through which only the nonvisible part of the solar spectrum is converted.

Lunt et al. were the first to propose a real selective TPV back in 2011 based on an organic planar heterojunction composed of a donor chloroaluminum phtalocyanine and $\mathrm{C}_{60}$ as an acceptor which achieved 1.3\% PCE with an AVT of $65 \%$ and 1.7\% PCE with 57\% AVT when including a back-positioned NIR Bragg mirror. ${ }^{12}$ This efficiency reached a PCE of $4 \%$ and an AVT of $64 \%$ by adopting a bulk heterojunction architecture based on PBDTT-DPP and PCBM polymers. ${ }^{13}$ The American

Received: February 3, 2021

Published: March 29, 2021

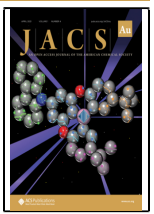


company Ubiquitous Energy, who has recently announced a TPV production line, achieved a Newport certification of $5.1 \%$ PCE and 51.5\% AVT by means of a single junction NIRselective excitonic semiconductors converting between 650 and $900 \mathrm{~nm} .{ }^{14}$ Conversion of near-UV light by combining a pair of wide-bandgap organic semiconductors has also been proposed recently reaching a PCE of ca. $1.2 \% .{ }^{15} \mathrm{~A}$ recent review on semitransparent polymer and perovskite solar cells provides state-of-the art progress in this field. ${ }^{16}$ Today, luminescence solar concentrator technology reaches the highest level of AVT, up to $88.3 \%$; however with only $0.4 \%$ PCE owing to the low cross-section absorption of NIR-light on glass edges. $^{17}$

The optical rendering of dye-sensitized solar cell (DSSC) technology is particularly advantageous since both coloration and level of transparency can be finely adjusted through materials and electrode thickness. Extending the light absorption from visible toward the near-infrared (NIR) region was rapidly targeted to reach panchromatic light absorption for improving the PCE of DSSCs. ${ }^{18-28}$ Differently, Han et al. reported in 2014 a green-colored see-through DSSC with a PCE of $3.66 \%$ and a peak maximum transmittance value of $60 \%$ at $560 \mathrm{~nm}$. This green semitransparent technology is based on the cosensitization between two efficient dyes absorbing in the visible range, one short $\mathrm{D}-\pi-\mathrm{A}$ dye (Y1) for blue-light conversion $(\lambda=400 \mathrm{~nm})$ and a central-modified squaraine dye (HSQ5) absorbing in the red region $(\lambda=700$ $\mathrm{nm}$ ) leaving an absorption valley in the green. ${ }^{29}$ A photochromic semitransparent DSSC was also proposed by Demadrille et al., who reported an AVT value of 59\% in the dark without photovoltaic activity. The AVT value decreases to $27 \%$ under illumination affording the possibility to convert sunlight with a maximum of PCE of $3.7 \% .^{30}$

Semitransparent DSSCs based on a visible absorbing dye (N719) was also proposed recently by Mallick et al., who reported a maximum AVT of $44 \%$ depending on the photoanode thickness with an efficiency of $2.4 \% .^{31,32}$ The authors introduced important metrics to assess the visual comfort of DSSCs for smart glazing applications, namely the color rendering index (CRI) and correlated color temperature (CCT) for which they reported CRI values between 83 and 93\%, and CCT values between 4647 and $5500 \mathrm{~K}$ in their different publications on semitransparent DSSC technology.

Toward the development of a selective NIR sensitizer with absorption going well-beyond $700 \mathrm{~nm}$, metal-free organic polymethine dyes are the most promising, ranging from squaraines, ${ }^{33-45}$ croconines, $^{46,47}$ to cyanines. ${ }^{4-52}$ The most remarkable achievement has been reported by Arakawa et al., who proposed a heptamethine cyanine dye decorated with a benzo-condensed heteroaromatic unit allowing the singlet-tosinglet absorption to be shifted to $822 \mathrm{~nm}$ with a high molar extinction coefficient $(\varepsilon)$ of $146000 \mathrm{~L} / \mathrm{mol} \cdot \mathrm{cm} .^{50}$ The final device reached a record PCE of $2.3 \%$, however requiring an opaque photoanode of $25 \mu \mathrm{m}$ thickness to reach this level of efficiency.

In this work, a series is reported of new symmetrical NIRselective heptamethine cyanine dyes, coded VG20- $\mathrm{C}_{x}$, inspired by the seminal work of Arakawa et al. ${ }^{50}$ The originality in these new dyes lies in two aspects. First, it bears two carboxylic acid anchoring groups conjugated to the condensed benzoindolenine lateral unit for stronger binding to the surface of $\mathrm{TiO}_{2}$ nanocrystals. Second, longer side alkyl chains are introduced to impede the formation of H-type aggregation which are harmful not only for device performance but also for strengthening the cell coloration, thus reducing both cell transmittance and color rendering. As a result, a PCE record of $3.1 \%$ for selective NIR-DSSC was achieved and a maximum of $76 \%$ AVT is demonstrated thanks to a holistic reduction of optical losses and a further red-shifted conversion maximum at $850 \mathrm{~nm}$, that goes well beyond our cones' sensitivity limit. The rate-limiting processes and the future challenges to level up the performances of this class of selective NIR-DSSCs are herein discussed based on ultrafast time-resolved spectroscopies.

\section{RESULTS AND DISCUSSION}

\section{Synthesis and Characterization of VG20-C 16 in Solution}

This work relies on the synthesis of a series of symmetrical heptamethine dyes, coded VG20- $\mathrm{C}_{x}$, with $x$ values varying from 2 to 16 carbons on the alkyl chain (Figure 1). The trans

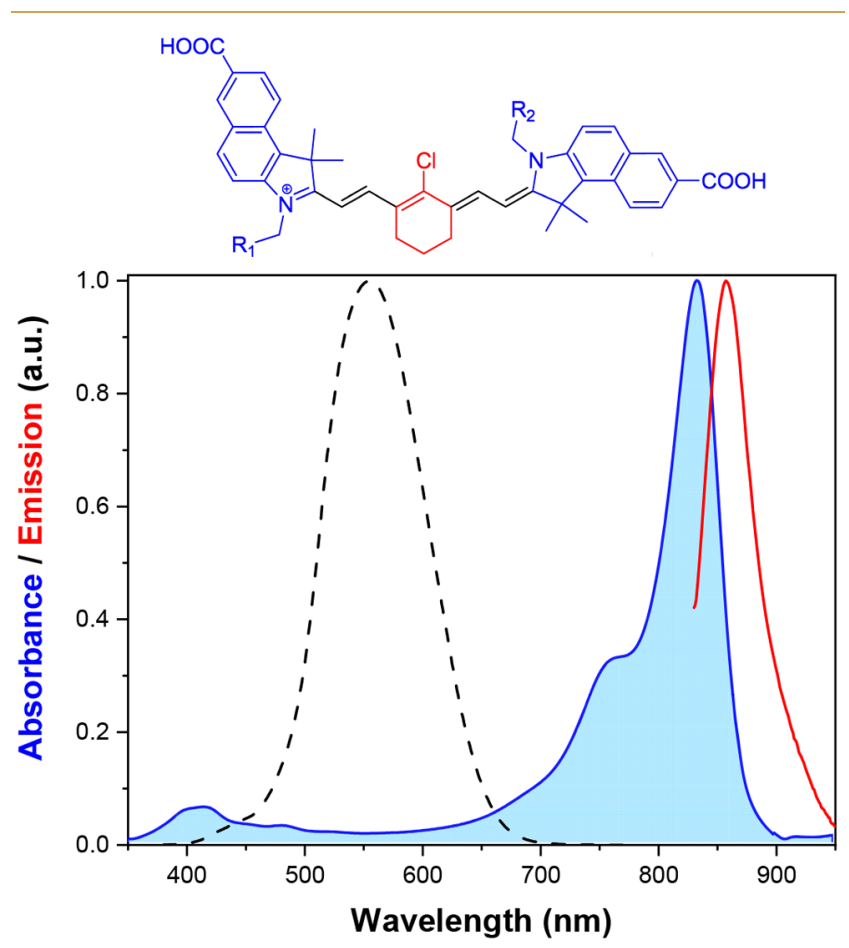

Figure 1. General chemical structure of VG20- $\mathrm{C}_{x}$ dye with $\mathrm{R}_{1}=\mathrm{R}_{2}=$ $\mathrm{C}_{2} \mathrm{H}_{5}, \mathrm{C}_{8} \mathrm{H}_{17}$, or $\mathrm{C}_{16} \mathrm{H}_{33}$ investigated in this study. Normalized UVvisible absorption spectrum of VG20- $\mathrm{C}_{16}$ in solution (blue curve) and steady-state photoluminescence (red curve) in 9/1 (v/v) ethanol/ DMSO solvent mixture (dye concentration $100 \mu \mathrm{mol} / \mathrm{L}, \mathrm{CDCA}$ concentration $50 \mathrm{mmol} / \mathrm{L}$ ). The photopic response of the human eye is represented as a black dashed line for comparison.

configuration of the polymethine bridge is stabilized by a classical cyclohexene moiety, substituted by a chlorine atom. The two $1 H$-benzo[e]indole end units, different from the analogous dyes reported by Arakawa et al., ${ }^{50}$ are decorated with a carboxylic acid in position 7 . The central chlorine has an electron withdrawing property and contributes to pulling electrons from the polymethine chain causing the dye's absorbance to shift in the NIR region. Besides facilitating the ability to scale up syntheses, the rationale behind the synthesis of symmetrical dyes, in which the anchoring groups are directly conjugated on the lateral heteroaromatic groups, is also to further red-shift the absorption maxima as previously demonstrated on symmetrical squaraines. ${ }^{42,45,53}$ This molec- 

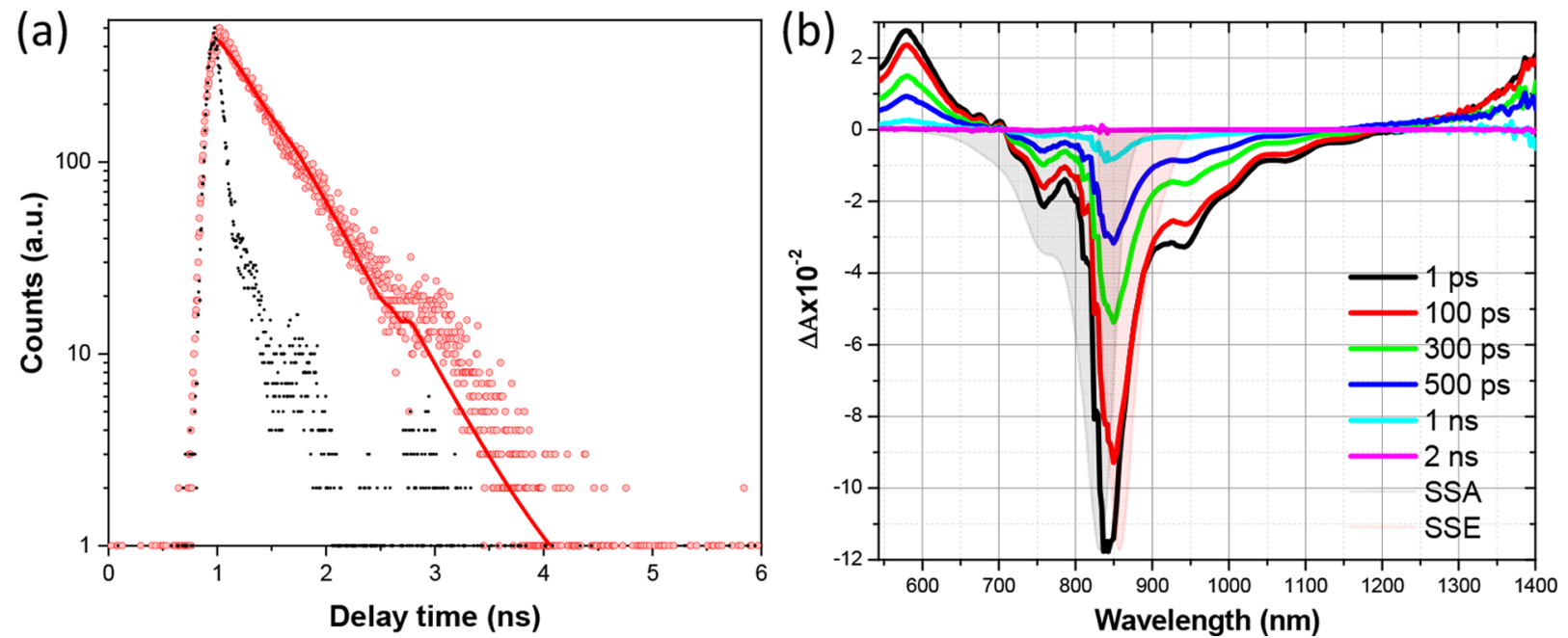

Figure 2. Time-resolved study of VG20-C ${ }_{16}$ dye $(100 \mu \mathrm{mol} / \mathrm{L})$ in $9 / 1$ ethanol/DMSO solvent mixture including $50 \mathrm{mmol} / \mathrm{L}$ of CDCA by (a) time-correlated single photon counting with an excitation at $640 \mathrm{~nm}$, emission probed at $860 \mathrm{~nm}$, and (b) femtosecond pump-probe transient absorption spectra at different delays. The excitation was at $810 \mathrm{~nm}$ with a $90 \mu \mathrm{J} / \mathrm{cm}^{2}$ pulse energy.

ular design, inspired by Arakawa's work and our previous work on squaraines, affords a better overlap between the lowest unoccupied molecular orbital (LUMO) of the dye and the conduction band (CB) of $\mathrm{TiO}_{2}$ to favor charge injection. ${ }^{42}$

VG20- $C_{16}$ in solution exhibits a sharp and intense absorption band in the NIR region with a maximum at $\lambda_{\max }$ $=834 \mathrm{~nm}(\varepsilon=154000 \mathrm{~L} / \mathrm{mol} \cdot \mathrm{cm})$ corresponding to the $\mathrm{S}_{0}-$ $S_{1}$ electronic transition (Figure 1). The shoulder at $765 \mathrm{~nm}$ principally relates to vibronic states in the molecule. However, as it will be discussed in the following, $\mathrm{H}$-aggregation of molecules composing the self-assembled monolayer also influences the relative intensity ratio of this shoulder with respect to the main electronic transition. Higher energy singlet transitions $\left(S_{0}-S_{n}\right)$ only lead to a residual broad and relatively weak absorption in the blue region (ca. $410 \mathrm{~nm}$ ), thus suitable for light transparency purposes. The fluorescence of VG20-C 16 exhibits a sharp emission band at $\lambda_{\max }=850 \mathrm{~nm}$ leading to a narrow Stokes shift of $225 \mathrm{~cm}^{-1}$. The vertical excitation energy is $E_{0-0}=1.47 \mathrm{eV}$, a value remarkably close to the optical bandgap $\left(E_{\mathrm{g}}=1.49 \mathrm{eV}\right)$ which means that VG20-type dyes in solution undergo negligible structural rearrangements in the excited-state, thus limiting intramolecular energy losses. It has a high photoluminescence quantum yield (PLQY) of $47 \%$, which makes this class of cyanine dyes also attractive for NIR fluorescent labeling. ${ }^{54-56}$

The systematic increase of the chenodeoxycholic acid (CDCA) concentration into VG20 dye solution has no influence either on the shoulder amplitude or on the width of the absorption band (Figure S1). This indicates that H-type aggregates are unlikely to form in the EtOH/DMSO solvent mixture $(9 / 1$ ratio, $\mathrm{v} / \mathrm{v})$ at a dye concentration of $100 \mu \mathrm{mol} / \mathrm{L}$.

Electronic structure calculations point out that the VG20 dye can coexist in two stable conformational isomers (cis and trans) given by the double bonds of the polymethine chain. The trans-conformation is $1.3 \mathrm{kcal} \cdot \mathrm{mol}^{-1}$ higher in energy than the cis-isomer. Hence, the latter represents more than $90 \%$ of the entire population in solution at room temperature. The electronic spectrum in vacuum of the cis-VG20 has been computed using the second-order algebraic-diagrammaticconstruction $\mathrm{ADC}(2)$ level of theory. It shows a strong absorption at $832 \mathrm{~nm}$ corresponding to the first excited singlet state $S_{0} \rightarrow S_{1}$ in agreement with the experimental data. The $S_{1}$ singlet state is assigned to a $\pi-\pi^{*}$ HOMO to LUMO transition. The calculated molecular frontier orbitals involve almost exclusively the polymethine chain (Figure S2). The theoretical analysis does not show any additional electronic transition at around $750 \mathrm{~nm}$, in agreement with the above assignment of a vibronic transition. Computational details and further spectral assignments are provided in Table S1. The HOMO and LUMO energy positions were determined by cyclic voltammetry (Figure S3). The two quasi-reversible peaks at $+0.24 \mathrm{~V}\left(\mathrm{vs} \mathrm{Fc}^{+} / \mathrm{Fc}\right)$ and $+0.57 \mathrm{~V}\left(\mathrm{vs} \mathrm{Fc}^{+} / \mathrm{Fc}\right)$ are attributed to the HOMO and HOMO +1 energy levels. The LUMO level is situated at $-1.06 \mathrm{~V}$ (vs $\left.\mathrm{Fc}^{+} / \mathrm{Fc}\right)$. These values lead to the HOMO and HOMO +1 at +0.87 and $+1.20 \mathrm{~V}$ (vs NHE), respectively, and the LUMO level at $-0.43 \mathrm{~V}$ (vs NHE), considering the $\mathrm{Fc}^{+} / \mathrm{Fc}$ redox potential at $+0.63 \mathrm{~V}$ vs NHE. ${ }^{57}$ The dye regeneration is thus thermodynamically favorable with both $\mathrm{I}_{3}{ }^{-} / \mathrm{I}^{-}(+0.35 \mathrm{~V}$ vs NHE$)$ and $\mathrm{Co}(\mathrm{bpy})_{3}{ }^{3+/ 2+}(+0.56 \mathrm{~V}$ vs $\mathrm{NHE}$ ) redox couples. However, we can postulate more difficulties for the electron injection step $\left(E_{\mathrm{CB}, \mathrm{TiO} 2} \approx-0.45\right.$ $\mathrm{V}$ vs $\mathrm{NHE}^{58}$ ) owing to a lack of an energetic driving force.

The photodynamic study of VG20-C 16 in solution has been carried out combining picosecond time-correlated single photon counting (TCSPC) and femtosecond time-resolved transient absorption spectroscopy (TAS) to assess the kinetics of both radiative and nonradiative deactivation processes (Figure 2). The photoluminescence (PL) decay shows two subnanosecond components: $\tau_{1}=391 \mathrm{ps}(f=93 \%)$ and $\tau_{2}=$ 925 ps attributed to the coexistence between the cis $\left(\tau_{1}\right)$ and trans $\left(\tau_{2}\right)$ forms in solution (Figure $2 \mathrm{a}$ ). These values are significantly faster compared to the benchmark ruthenium or organic dyes used in DSSCs which lie between 2 and 100 ns. ${ }^{45,59-61}$ This is due to the highly bound Frenkel excitons in the cyanine backbone structure leading to a comparatively poorer electron/hole delocalization in the excited states as it is also indicated by the calculation of the molecular frontier orbitals. The side-alkyl chain length and the CDCA content in solution have no noticeable influence on the excited-state dynamics (Figures S4-S5). Similar kinetics were measured by fs-TAS. Upon excitation with a $50 \mathrm{fs}$ pulse at $810 \mathrm{~nm}, \mathrm{VG} 20$ $\mathrm{C}_{16}$ exhibits pronounced excited state signatures, such as 

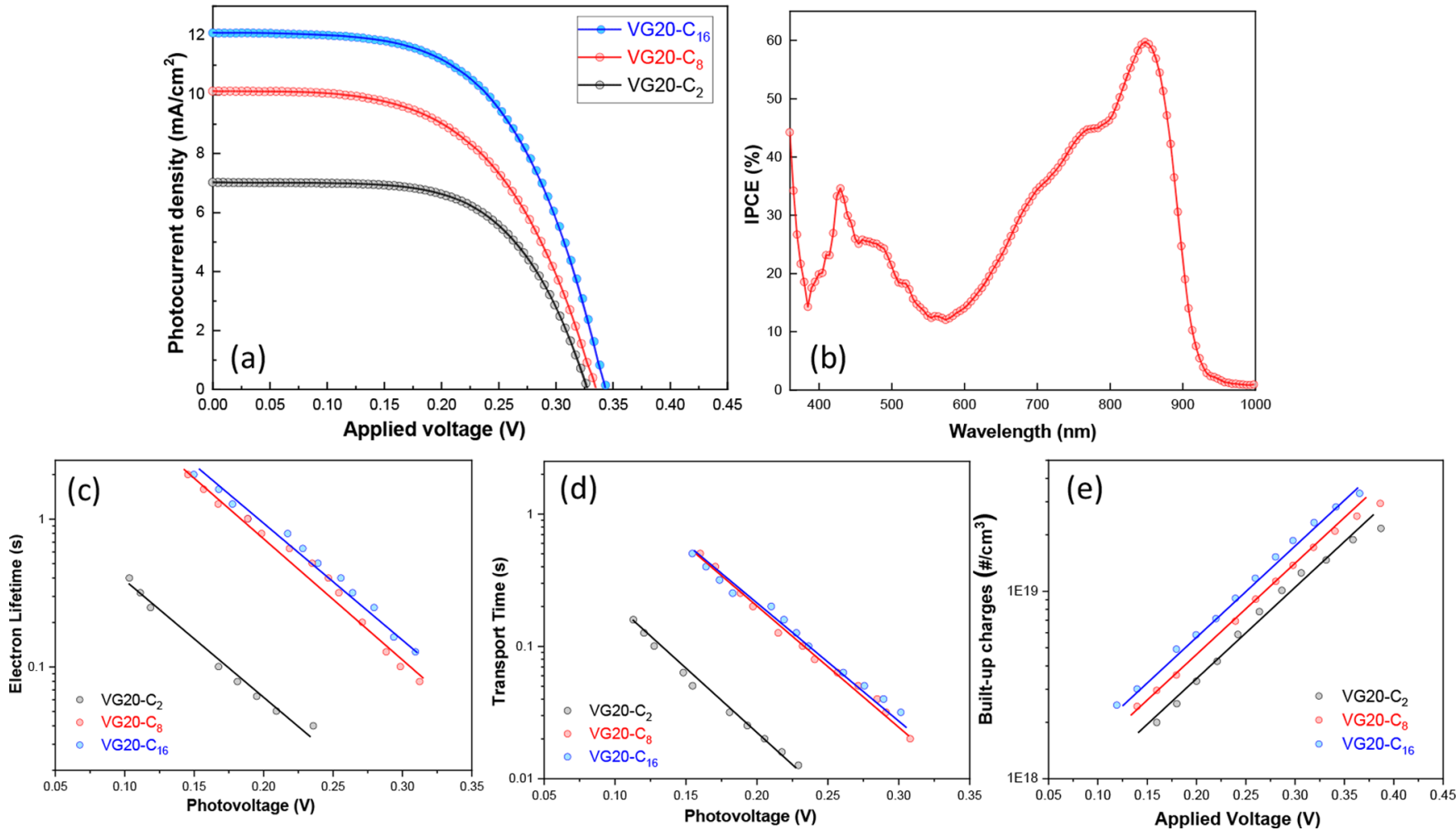

Figure 3. (a) $J-V$ curve under illumination at A.M. $1.5 \mathrm{G}$ conditions of VG20 dye as a function of the alkyl chain length for $\mathrm{C}_{2}$ (black curve), $\mathrm{C}_{8}$ (red curve), and $\mathrm{C}_{16}$ (blue curve). (b) IPCE spectrum of a VG20-C $\mathrm{C}_{16}$ based DSSC and (c) IMVS, (d) IMPS, and (e) dark charge extraction measurements of VG20 dye as a function of the alkyl chain length for $\mathrm{C}_{2}$ (black curves), $\mathrm{C}_{8}$ (red curves), and $\mathrm{C}_{16}$ (blue curves) (the electrolyte composition is $1 \mathrm{~mol} / \mathrm{L}$ DMII, $0.03 \mathrm{~mol} / \mathrm{L} \mathrm{I}_{2}$, and $1 \mathrm{~mol} / \mathrm{L} \mathrm{LiI}$ in the acetonitrile/valeronitrile solvent mixture $(85 / 15 \mathrm{v} / \mathrm{v})$, and the devices are made of $8 \mu \mathrm{m}$ thick $20 \mathrm{~nm}$-based $\mathrm{TiO}_{2}$ nanoparticles sheltered by $5.5 \mu \mathrm{m}$ thick $400 \mathrm{~nm} \mathrm{TiO}_{2}$ particles).

excited state absorption (ESA) below $670 \mathrm{~nm}$ and beyond 1.3 $\mu \mathrm{m}$ (positive signal) and stimulated emission (SE) between 850 and $1100 \mathrm{~nm}$, partially overlapping with ground state bleach (GSB) in the 700-900 $\mathrm{nm}$ range (Figures $2 \mathrm{~b}, \mathrm{~S} 6$ ). Kinetic traces taken in the maximum of ESA, SE, and GSB decay in parallel, and individual wavelength fits give decay times in the range of 360 to 410 ps (Table S2). An additional rise component, in the range of $1-2$ ps is also observed, most likely due to intramolecular relaxation and solvation dynamics in the EtOH/DMSO (9/1) mixture.

\section{Rational Optimization of the Device Performance and Transparency}

Since cyanines molecules are notorious for forming aggregates, the above results indicating the absence of aggregation in solution when combining ethanol/DMSO solvent mixture and low dye concentration of $100 \mu \mathrm{mol} / \mathrm{L}$ is important. However, the addition of CDCA as a deaggregating agent in the dyeing solution remains compulsory for the device performance to avoid quenching of the excited states that penalizes high yield of electron injection ${ }^{62-64}$ and to maintain a colorless aspect of the photoanode (Figure S7). This work raises multiple points of evidence that strong H-type and J-type aggregates are formed within the self-assembled monolayer (SAM). This constitutes a major limitation not only for the device performance but also for the aesthetic as will be further discussed. The best conversion performances are obtained using a highly diluted dye solution $(100 \mu \mathrm{mol} / \mathrm{L})$ including 50 $\mathrm{mmol} / \mathrm{L}$ of CDCA (1/500 ratio). Increasing the CDCA concentration to such an extent reduces the level of aggregation but also decreases the dye loading because the dye chemisorption enters into competition with CDCA coadsorption. ${ }^{65}$

Different alkyl chain lengths from $\mathrm{C}_{2}$ to $\mathrm{C}_{16}$ were synthesized to hamper tail-to-tail dye aggregation. ${ }^{66}$ It has no influence on the energy positions of both HOMO and LUMO orbitals. However, the longer the alkyl chain, the higher the molar extinction coefficient. A very slight red-shift by $6 \mathrm{~nm}$ of the singlet-to-singlet transition is also noticed (Figure S8). Optimizing the alkyl chain length contributes noticeably to the device performance, i.e., from 1.5\% PCE for VG20- $\mathrm{C}_{2}, 1.9 \%$ for VG20-C $\mathrm{C}_{8}$, and 2.5\% PCE for VG20-C $\mathrm{C}_{16}$ (Figure 3a, Table S3). This improvement stems mainly from the photocurrent, increasing from 7.1 to $12.0 \mathrm{~mA} / \mathrm{cm}^{2}$, and to the cell photovoltage to a lower extent. To achieve these performances, the typical Lewis acid 4-tert-butylpyridine (4-TBP) and the guanidinium thiocyanate $(\mathrm{GuSCN})$ are removed from the electrolyte to downshift the $\mathrm{TiO}_{2}$ conduction band edge. ${ }^{67-70}$ The electrolyte also includes a high concentration of lithium (1 $\mathrm{mol} / \mathrm{L}$ ) as will be discussed in the following. The incident photon to current efficiency (IPCE) spectrum shows a maximum of $60 \%$ at $850 \mathrm{~nm}$ leading after integration to a maximum $J_{\mathrm{sc}}$ value of $11.6 \mathrm{~mA} / \mathrm{cm}^{2}$ (Figure $3 \mathrm{~b}$ ). Although the $\mathrm{S}_{0}-\mathrm{S}_{n}$ transitions are only weakly absorbing, they still provide ca. 30\% IPCE indicating that conversion of high energy photons is an efficient process within this type of dye.

Intensity modulated photovoltage/photocurrent spectroscopy (IMVS/PS) experiments highlight that the alkyl chain length affects both nongeminate recombination and electron transport (Figure $3 c, d$ ). Indeed, whereas $\mathrm{C}_{8}$ and $\mathrm{C}_{16}$ behave very comparably, reducing the number of carbon to $\mathrm{C}_{2}$ leads to 
a shortening of electron lifetime by ca. 1 order of magnitude and the transport time to a lesser extent. The electron transport is affected since the surface trapped electrons and the chemisorbed lithium are forming a quasi-particle contributing to an ambipolar transport of carriers toward the collection. ${ }^{71,72}$ The charge collection efficiency $\left(\eta_{\mathrm{cc}}\right)$, expressed as the time ratio between the electron lifetime and the sum of electron lifetime and transport time, is enhanced by extending the length of the alkyl chain, from $\eta_{\mathrm{cc}}=70 \%$ for $\mathrm{C}_{2}$ to $\eta_{\mathrm{cc}}=80 \%$ for $\mathrm{C}_{8}$ and $\mathrm{C}_{16}$. These results suggest, in agreement with previous literature, that longer alkyl chain length helps to repel tri-iodide species from the $\mathrm{TiO}_{2}$ surface. Additional charge extraction experiments confirm that it modifies the SAM molecular packing based on the movement of the trap state energy driven by a different interfacial electric field strength (Figure 3e). The $15 \mathrm{mV}$ gain in photovoltage experimentally observed is thus the result of the combination between the 1 order of magnitude longer electron lifetime (+59 mV expected) and $40 \mathrm{mV}$ energy downshift of the traps.

Small alkali cations, such as $\mathrm{Li}^{+}$, are known for their specific adsorption properties upon $\mathrm{TiO}_{2}$ surfaces. Its Coulombic interaction with the surface of $\mathrm{TiO}_{2}$ nanocrystals increases the flat band potential value, which moves the conduction band edge and surface traps down proportionally to the Nernst equation, i.e. $59 \mathrm{mV}$ per decade of concentration. ${ }^{45,71,72}$ In the case of the VG20- $\mathrm{C}_{16}$ dye, a high concentration of $1 \mathrm{~mol} / \mathrm{L}$ of $\mathrm{Li}^{+}$in the electrolyte is required to reach a short-circuit current density of $12.1 \mathrm{~mA} / \mathrm{cm}^{2}$ (Figure S9, Table 1). Nevertheless,

Table 1. Cell Characteristics Depending on the Lithium Concentration in the Electrolyte for VG20-C $\mathrm{C}_{16}$-Based DSSCs $^{a}$

$\begin{array}{ccccc}\mathrm{Li}^{+} \text {concentration } & V_{\text {oc }}(\mathrm{mV}) & J_{\text {sc }}\left(\mathrm{mA} / \mathrm{cm}^{2}\right) & \text { fill factor }(\%) & \text { PCE (\%) } \\ 0.1 \mathrm{~mol} / \mathrm{L} & 395 & 5.5 & 66 & 1.6 \\ 0.25 \mathrm{~mol} / \mathrm{L} & 375 & 8.4 & 58 & 1.9 \\ 0.5 \mathrm{~mol} / \mathrm{L} & 368 & 9.6 & 56 & 2.2 \\ 1.0 \mathrm{~mol} / \mathrm{L} & 347 & 12.1 & 58 & 2.5\end{array}$

${ }^{a}$ Electrolyte composition is $1 \mathrm{~mol} / \mathrm{L} \mathrm{DMII}, 0.03 \mathrm{~mol} / \mathrm{L} \mathrm{I}_{2}$, and $1 \mathrm{~mol} /$ $\mathrm{L} \mathrm{LiI} \mathrm{in} \mathrm{acetonitrile/valeronitrile} \mathrm{solvent} \mathrm{mixture} 85 / 15 \mathrm{v} / \mathrm{v}$.

this enhancement is at the expense of the cell photovoltage, which decreases by a value close to the $59 \mathrm{mV}$ expected thermodynamically from Nernst equation (from 395 to 347 $\mathrm{mV})$.

In addition to the CDCA and the alkyl chain length, the sensitization temperature modifies the dye packing as previously demonstrated on ruthenium-based complexes and also showed here by different data. ${ }^{73}$ Three different temperatures have been investigated: room-temperature (RT), 4, and $-20{ }^{\circ} \mathrm{C}$. To compensate for the slower dye chemisorption, the sensitization time has been prolonged from $12 \mathrm{~h}$ to 7 days at $-20{ }^{\circ} \mathrm{C}$ to maintain similar dye loading on the photoanode (Figure S10). Without dramatically losing the cell photocurrent, it increases both the fill factor and the cell photovoltage, thanks to a reduction of the nongeminate recombination kinetics (Figures 4 and S11). A PCE maximum of $3.1 \%$ can be achieved after sensitizing the electrodes at -20 ${ }^{\circ} \mathrm{C}$ while applying rigorously all aforementioned optimization steps (Table 2).

The stability of polymethine-based sensitizers has never been demonstrated so far in the literature. This is one drawback of this family of dyes. We identified water molecules

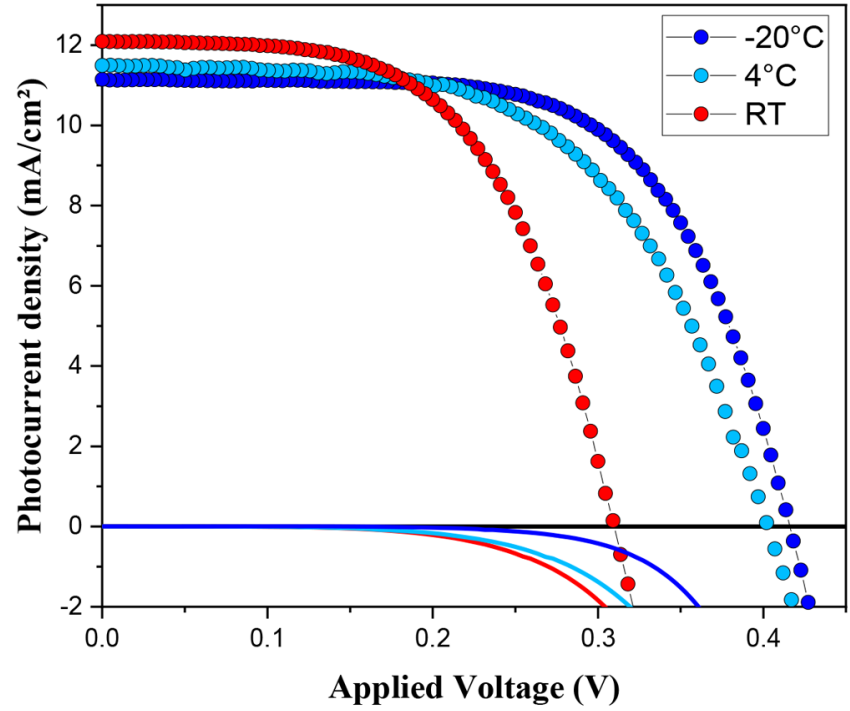

Figure 4. $J-V$ curve under illumination at A.M. 1.5G conditions of the VG20-C $\mathrm{C}_{16}$-based DSSC as a function of the temperature of sensitization, RT (red), $4{ }^{\circ} \mathrm{C}$ (light blue), and $-20{ }^{\circ} \mathrm{C}$ (blue dark) (the electrolyte composition is $1 \mathrm{~mol} / \mathrm{L}$ DMII, $0.03 \mathrm{~mol} / \mathrm{L} \mathrm{I}_{2}$, and 1 $\mathrm{mol} / \mathrm{L} \mathrm{LiI} \mathrm{in} \mathrm{the} \mathrm{acetonitrile/valeronitrile} \mathrm{solvent} \mathrm{mixture} \mathrm{(85/15} \mathrm{v/}$ $\mathrm{v})$, and the devices are made of $8 \mu \mathrm{m}$ thick $20 \mathrm{~nm}$-based $\mathrm{TiO}_{2}$ nanoparticles sheltered by $5.5 \mu \mathrm{m}$ thick $400 \mathrm{~nm} \mathrm{TiO}_{2}$ particles).

Table 2. Cell Characteristics Depending on the Sensitization Temperature VG20-C ${ }_{16}$-Based DSSCs

\begin{tabular}{lcccc} 
temperature & $V_{\text {oc }}(\mathrm{mV})$ & $J_{\text {sc }}\left(\mathrm{mA} / \mathrm{cm}^{2}\right)$ & fill factor $(\%)$ & PCE (\%) \\
RT & 343 & 12.0 & 58 & 2.5 \\
$4{ }^{\circ} \mathrm{C}$ & 402 & 11.5 & 58 & 2.6 \\
$-20{ }^{\circ} \mathrm{C}$ & 422 & 11.2 & 65 & 3.1 \\
\hline
\end{tabular}

as one major factor impacting the device stability. An enhancement of shelf life stability can be attained by assembling the devices in dry room (dew point temperature below $-75^{\circ} \mathrm{C}$ ), drying solvents and electrolyte components carefully before using. Replacing the EtOH/DMSO solvent mixture for sensitization by DCM/DMSO affords improvement in the devices shelf life stability with a PCE retention over $92 \%$ for $400 \mathrm{~h}$ (Figure S12).

Replacing the tri-iodide/iodide redox mediator by $\mathrm{Co}(+\mathrm{III} /$ + II) complexes affords reducing energy losses for the dye regeneration and circumventing the device orange coloration. ${ }^{74-80}$ NIR photosensitizers associated with cobalt-based electrolytes have not been explored so far. Using a $\mathrm{Co}(\mathrm{bpy}) 3^{3+/ 2+}$ redox couple, the optimized concentration of lithium for the device performance can be reduced down to 0.1 mol/L of LiTFSI (Table S4). This has the further advantage that, while maintaining the $J_{\mathrm{SC}}$ constant, the open circuit photovoltage $\left(V_{\mathrm{OC}}\right)$ increases from 358 to $387 \mathrm{mV}$. As a result, the best PCE is obtained with $0.1 \mathrm{~mol} / \mathrm{L} \mathrm{LiTFSI} \mathrm{in} \mathrm{the}$ electrolyte leading to $1.9 \%$. However, one drawback in the utilization of cobalt (+III/+II) complexes stems from the faster nongeminate recombination kinetics which herein limit the possible gain in photovoltage. ${ }^{81-84}$ To alleviate this issue, atomic layer deposition (ALD) has been employed to retard loss reactions at the $\mathrm{TiO}_{2} /$ dye/electrolyte interfaces. ${ }^{81,84-86}$ In this case, the best performances were obtained with an optimized subnanometric-thick $\mathrm{Ga}_{2} \mathrm{O}_{3}$ overlayer which acts as a tunnelling barrier to effectively balance injection and 

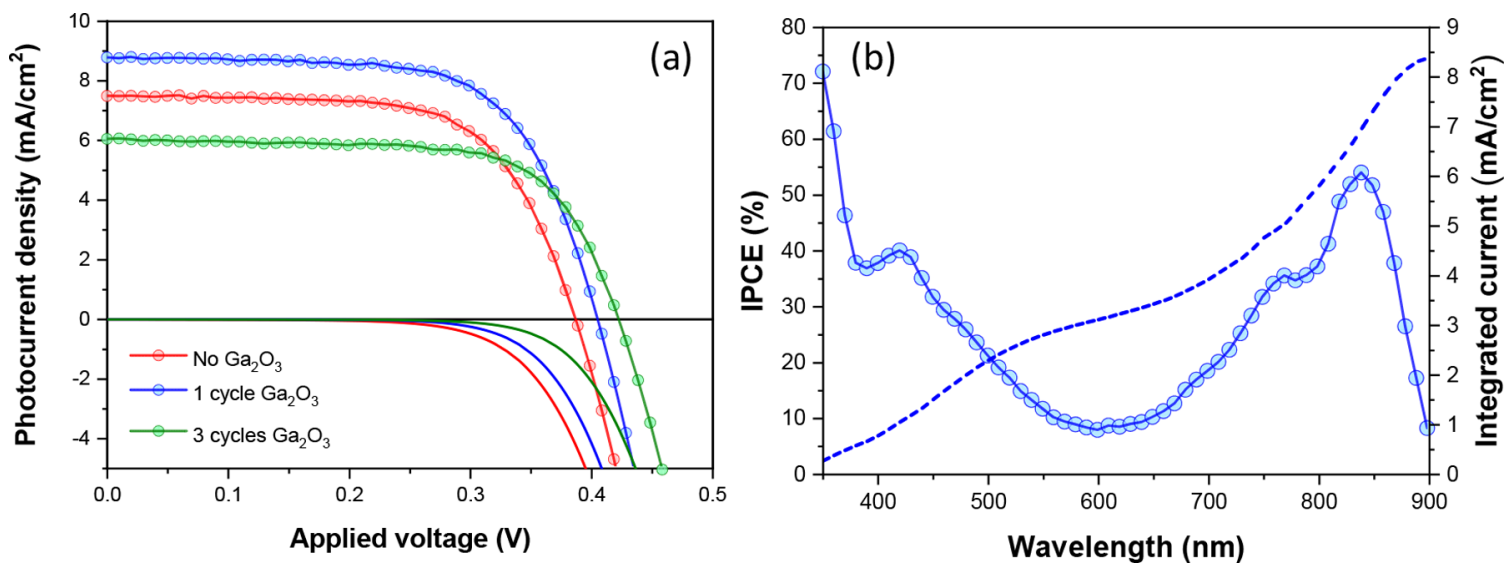

Figure 5. (a) $J-V$ curves for DSSC photoanodes subjected to different numbers of $\mathrm{Ga}_{2} \mathrm{O}_{3}$ ALD cycles under A.M. 1.5G conditions. (b) IPCE spectrum and integrated current density. (the electrolyte composition is $0.25 \mathrm{~mol} / \mathrm{L} \mathrm{Co}(\mathrm{bpy})_{3}{ }^{2+}, 0.05 \mathrm{~mol} / \mathrm{L} \mathrm{Co}(\mathrm{bpy})_{3}{ }^{3+}$, and $0.1 \mathrm{~mol} / \mathrm{L} \mathrm{LiTFSI}$ in the acetonitrile/valeronitrile solvent mixture $(85 / 15 \mathrm{v} / \mathrm{v})$, and the devices are made of $8 \mu \mathrm{m}$ thick $20 \mathrm{~nm}$-based $\mathrm{TiO}_{2}$ nanoparticles sheltered by 5.5 $\mu \mathrm{m}$ thick $400 \mathrm{~nm} \mathrm{TiO}_{2}$ particles).

recombination (Figure 5a). ${ }^{86}$ As a result, production of dark current is significantly blocked due to the kinetic hindrance of nongeminate recombination. With the deposition of a single layer, both the photovoltage and the photocurrent values are increased to $V_{\mathrm{OC}}=406 \mathrm{mV}, J_{\mathrm{SC}}=8.6 \mathrm{~mA} / \mathrm{cm}^{2}$ leading to a PCE of $2.3 \%$. The IPCE spectrum is very similar to tri-iodide/ iodide redox mediator with a maximum of $54 \%$ at $840 \mathrm{~nm}$. This latter is slightly blue-shifted due to existing electrostatic interactions between the dye and the redox mediator (Figure $5 b$ ). Thicker $\mathrm{Ga}_{2} \mathrm{O}_{3}$ deposition led to an increase of the photovoltage to $423 \mathrm{mV}$; however, the photocurrent dropped dramatically to $5.9 \mathrm{~mA} / \mathrm{cm}^{2}$ after 3 cycles, leading to a PCE of $1.7 \%$ (Table S5).

\section{Average Visible Transmittance and Color Rendering}

The level of device transparency was evaluated based on the average visible transmittance (AVT) considering not only the transmittance spectrum $(\mathrm{T})$ but also the visual perception of human eyes through the photopic response $(P)$ and the solar photon flux $(S)$ in A.M. 1.5G conditions according to the following equation: ${ }^{87}$

$$
\operatorname{AVT}=\frac{\int T(\lambda) P(\lambda) S(\lambda) \mathrm{d}(\lambda)}{\int P(\lambda) S(\lambda) \mathrm{d}(\lambda)}
$$

AVT is the most recommended assessment by the windows industry to evaluate the transparency level of TPVs. Figure 6a shows the total transmittance spectrum of full devices without dye and electrolyte (black curve) and with VG20-C $\mathrm{C}_{16}$ dye in either $\mathrm{I}_{3}{ }^{-} / \mathrm{I}^{-}$or $\mathrm{Co}(\text { bpy })_{3}{ }^{3+/ 2+}$ redox mediators. Taking advantage of VG20- $\mathrm{C}_{16}$ design, we matched remarkably the higher cell transmittance region to the maximum of the human eye's photopic response leading for the first time to completely transparent and colorless DSSC devices (Figure 6a). The electrolyte absorption shows up in the UV and blue region $(<500 \mathrm{~nm})$ : a region in which the human cones are much less sensitive. On the other hand, dye aggregation, featured by a broadening of the $S_{0}-S_{1}$ transition, has a slight effect in the red part tail of the photopic response (Figures S7, S13). The AVT of the reference device, i.e. complete cell without the dye, reaches a maximum value of $74 \%$ without subtraction of glass reflections; this latter accounts for $9.5-11 \%$ depending on the incident wavelength (Figure S14). The sensitization of the photoanode decreases the AVT value to $65 \%$ as a result of the aggregation-induced broadening of the $S_{0}-S_{1}$ transition and the $S_{0}-S_{n}$ transition in the blue part competing with the electrolyte absorption (Figure S13).

Devices based on tri-iodide/iodide redox couple has $x, y$ coordinates of 0.370 and 0.416 in the CIE1931 chromaticity diagram (Figure 6b). It corresponds to the light yellowish part of the color space in agreement with the visual aspect of the device reported in the inset of Figure 6a. It reaches a color rendering index (CRI) value of $88 \%$, and the correlated color temperature (CCT) is $5612 \mathrm{~K}$. The CRI is also an important metric to consider in TPV applications as it describes the quantitative accuracy of the color rendered through a transparent medium. A value greater than $85 \%$ is considered excellent for TPV technologies applied to building facades.

The utilization of cobalt complexes avoids this slight orange coloration of the electrolyte given by tri-iodide. It leads to a noticeable shift of the $x, y$ coordinates in the chromaticity diagram toward the center corresponding to the colorless region, i.e. $x=0.349$ and $y=0.360$ (Figure $6 \mathrm{~b}$ ). The CRI value increases to $92.1 \%$, and the CCT value is $5553 \mathrm{~K}$. The change to cobalt complexes influences a little of the absorption fingerprint of the dye. The $S_{0}-S_{1}$ maximum shifts from $848 \mathrm{~nm}$ for an $\mathrm{I}_{3}{ }^{-} / \mathrm{I}^{-}$-based electrolyte to $844 \mathrm{~nm}$ for $\mathrm{Co}(\mathrm{bpy})_{3}{ }^{3+/ 2+}$. The main absorption band becomes narrower, and the shoulder containing the spectroscopic signature of the $\mathrm{H}$ aggregates is less pronounced. These results suggest that the dye interacts very intimately with the redox mediator, influencing the SAM geometry and packing. Consequently, the AVT of devices based on $\mathrm{Co}(\mathrm{bpy}) 3^{3+/ 2+}$ reaches a value of $68 \%$ up to an electrode thickness of $4 \mu \mathrm{m}$. With this AVT value, our devices appear totally transparent and close to colorless, in agreement with that found by Lunt et al., who pointed out that an AVT value of $60 \%$ constitutes a threshold value from which the PV device becomes clear. ${ }^{14,88}$ Following a spin-coated layer of $\mathrm{SiO}_{2}$ nanoparticles as an antireflecting coating (ARC), we achieved an AVT value of $76 \%$ (Figure S15). Such a number achieved with a selective NIR-DSSC lies well beyond the values reported so far in semitransparent visible DSSCs. $^{29-32}$ It approaches very closely the AVT characteristic of a standard double glazed window which is $78 \%$. ${ }^{32}$ Optimizing the number of layers of $\mathrm{SiO}_{2}$ depositing 
(a)

(b)
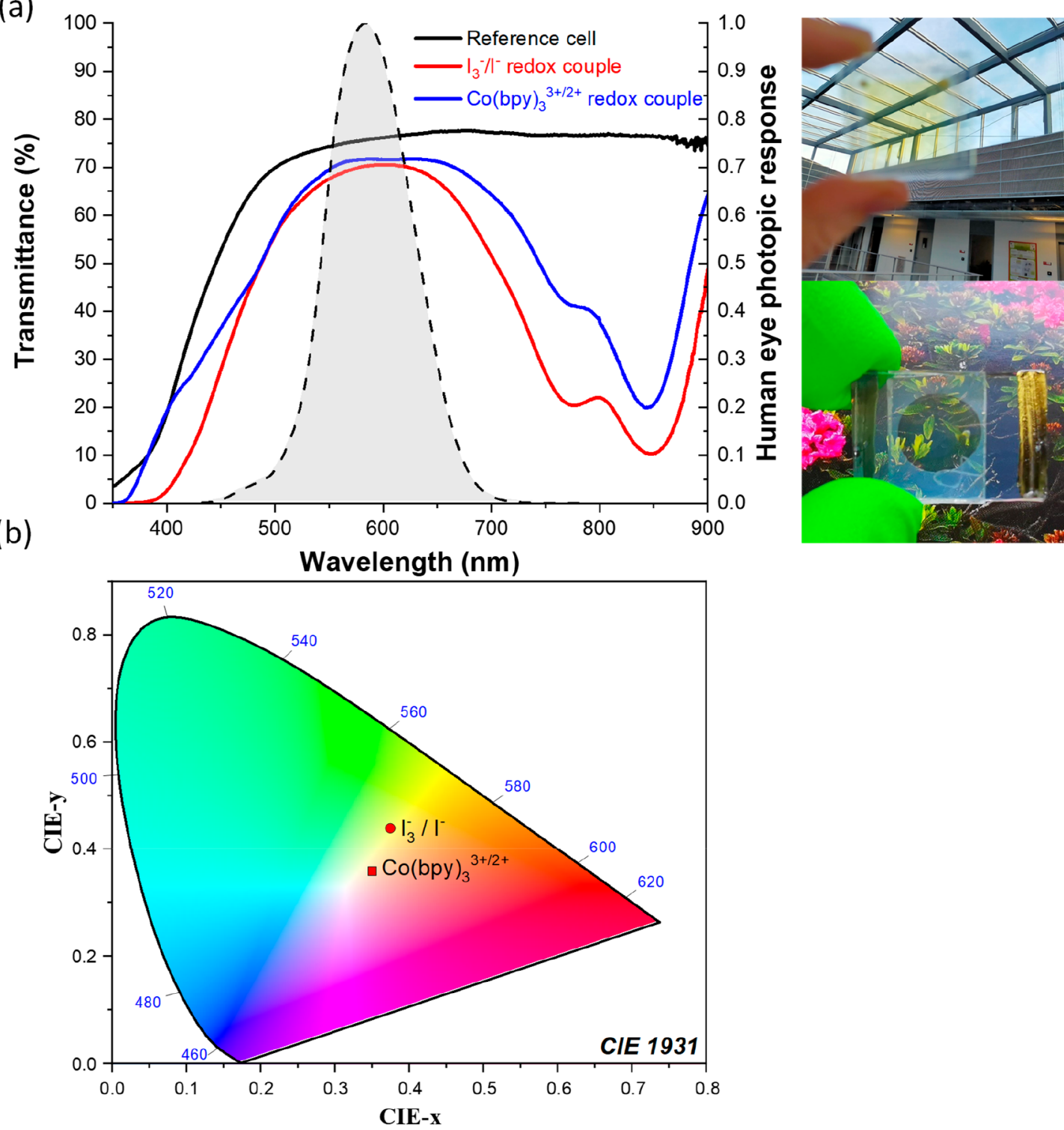

Figure 6. (a) Comparison of total cell transmittance measured using an integration sphere of a reference cell without dye and with an optimized electrolyte based on $\mathrm{I}_{3}{ }^{-} / \mathrm{I}^{-}$redox couple (black curve) and VG20-C $\mathrm{C}_{16}$ based devices constituted by an optimized electrolyte formulation based on the $\mathrm{I}_{3}{ }^{-} / \mathrm{I}^{-}$redox couple (red curve) and $\mathrm{Co}(\mathrm{bpy})_{3}{ }^{3+/ 2+}$ redox couple (blue curve) with the aforementioned composition. The photoanode thickness is $4.0 \mu \mathrm{m}$. The human eye photopic response is included for comparison with the eye's sensitivity. Two pictures of the transparent NIR-DSSC are also provided: (top) with the $\mathrm{I}_{3}{ }^{-} / \mathrm{I}^{-}$redox couple and (bottom) with the Co(bpy) ${ }_{3}^{3+/ 2+}$ redox couple. (b) CIE 1931 color space diagram for VG20$\mathrm{C}_{16}$ devices based on the $\mathrm{I}_{3}{ }^{-} / \mathrm{I}^{-}$or $\mathrm{Co}(\mathrm{bpy})_{3}{ }^{3+/ 2+}$ redox couples in the electrolyte.

allows increased cell transmittance in the NIR region and, therefore, a gain $0.2 \% \mathrm{PCE}$ in the final device performance.

\section{Dye Regeneration and Electron Injection Kinetics}

Dye regeneration kinetics have been evaluated using transient absorption spectroscopy associated with a streak camera for both spectral and temporal resolution of the transient dye radical cation. Figure 7 depicts the kinetic evolution depending on the electrolyte composition: i.e. $\mathrm{I}_{3}{ }^{-} / \mathrm{I}^{-}$redox mediator (Figure $7 \mathrm{a}), \mathrm{Co}(\mathrm{bpy})_{3}{ }^{3+/ 2+}$ (Figure $7 \mathrm{~b}$ ), or for a redox couplefree electrolyte (Figure $7 \mathrm{c}$ ). The $\mathrm{VG} 20-\mathrm{C}_{16}$ radical cation absorbs in the visible range in agreement with the literature. ${ }^{89}$ It shows up as a broad absorption spectrum between ca. 500 and $720 \mathrm{~nm}$ (Figure 7, Figure S16) for which the kinetics differ for the two redox mediators. The molar absorption coefficient of the dye radical cation in solution is about 25 times weaker compared to the reduced form in the same solution $(\varepsilon \approx 6200$ $\mathrm{L} / \mathrm{mol} \cdot \mathrm{cm}$ ) (Figure S17).

The related transient decay corresponds to the depopulation of the dye radical cation after a 30 ps pump pulse at $830 \mathrm{~nm}$ (Figure 8 ). The exponential decay requires systematically two components to account for fast and slower processes in regeneration involving $\mathrm{HOMO}$ and $\mathrm{HOMO}+1$ levels. For a $\mathrm{I}_{3}{ }^{-} / \mathrm{I}^{-}$redox couple, dye regeneration takes place within $\tau_{1}=$ $1.5 \mu \mathrm{s}( \pm 0.09 \mu \mathrm{s})$ and $\tau_{2}=19.4 \mu \mathrm{s}( \pm 1.3 \mu \mathrm{s})$. These values are the same order of magnitude as those reported for conventional ruthenium and $\mathrm{D}-\pi-\mathrm{A}$ dyes. ${ }^{45,90-92}$ Although the cobalt complex is a fast one-electron redox couple, the halftime for dye regeneration is about 1 order of magnitude longer, i.e. $\tau_{1}=15.6 \mu \mathrm{s}( \pm 0.4 \mu \mathrm{s})$ and $\tau_{2}=100.7 \mu \mathrm{s}( \pm 4.2 \mu \mathrm{s})$ as a result of the reduced driving force for the hole transfer, i.e. $-\Delta G_{\mathrm{reg}}^{\circ}=$ $520 \mathrm{mV}$ for $\mathrm{I}_{3}{ }^{-} / \mathrm{I}^{-}$and $-\Delta G_{\text {reg }}^{\circ}=310 \mathrm{mV}$ for $\mathrm{Co}(\mathrm{bpy})_{3}{ }^{3+}{ }^{2+}$. 


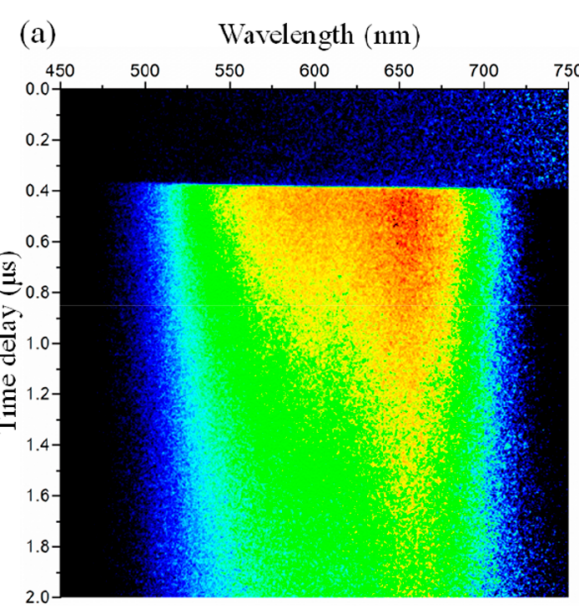

(b) Wavelength (nm)

(c)
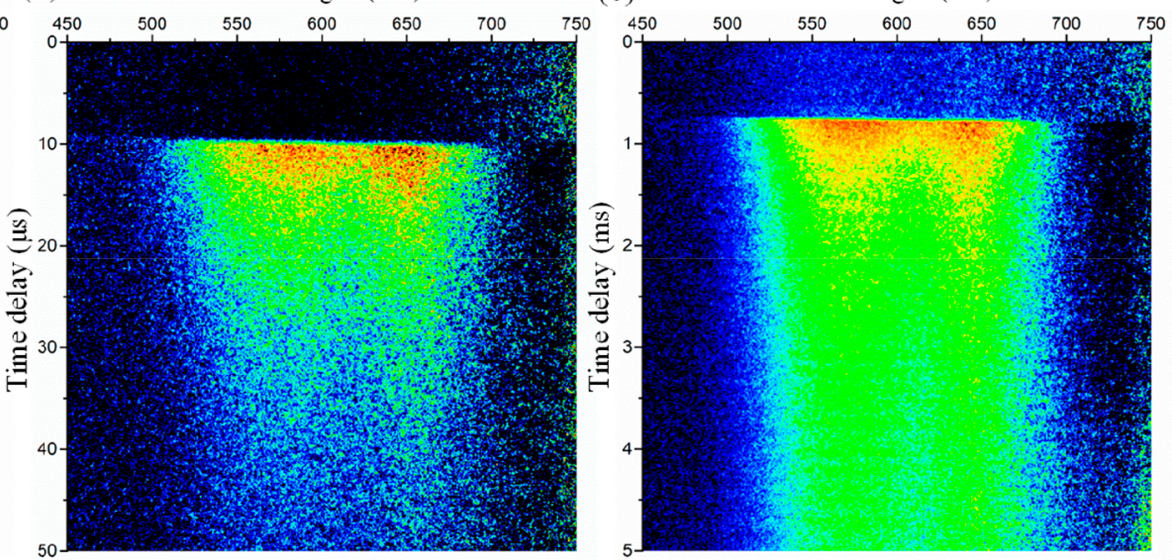

Figure 7. Time-resolved transient absorption spectral streak image of the VG20-C $\mathrm{C}_{16}$ based DSSC for (a) the $\mathrm{I}_{3}^{-} / \mathrm{I}^{-}$redox couple, (b) the $\mathrm{Co}(\text { bpy })_{3}{ }^{3+/ 2+}$ redox couple, and (c) the redox couple-free electrolyte. Note the difference of time delay between the different electrolytes.

(a)

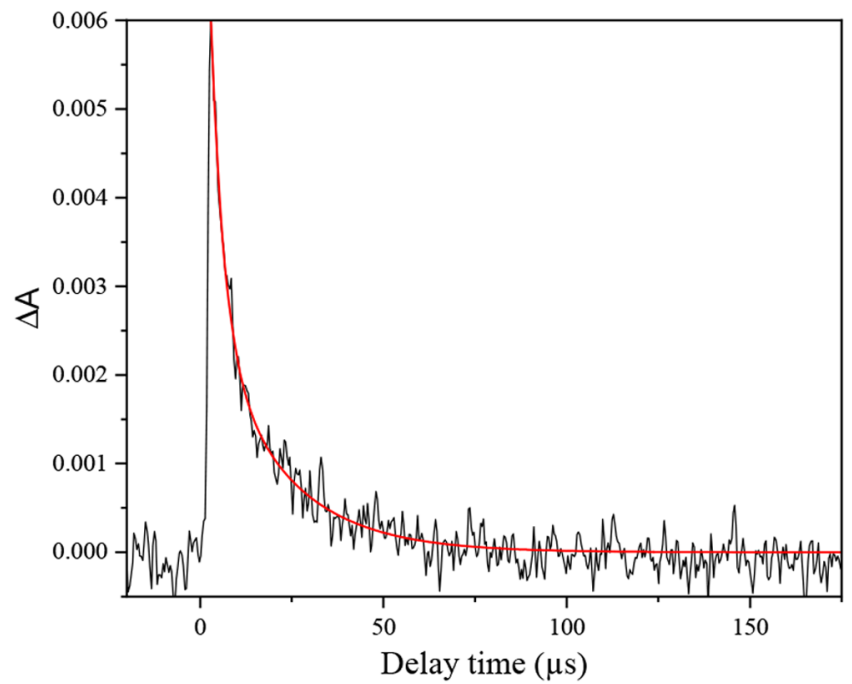

(b)

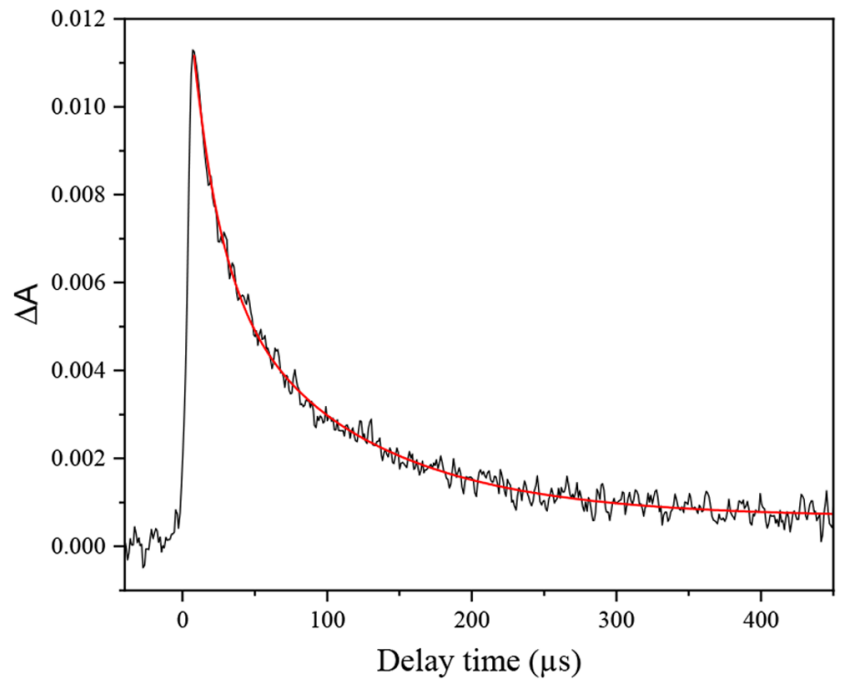

Figure 8. Transient absorption kinetics of the VG20-C ${ }_{16}$ based DSSC: (a) at $650 \mathrm{~nm}$ in the presence of the $\mathrm{I}_{3}^{-} / \mathrm{I}^{-}$redox couple and (b) at $550 \mathrm{~nm}$ in the presence the $\mathrm{Co}(\mathrm{bpy}){ }_{3}{ }^{3+/ 2+}$ redox couple $\left(E_{810 \mathrm{~nm}} \approx 0.18 \mathrm{~mJ} / \mathrm{cm}^{2}\right)$.

This range of values is also in agreement with the typical kinetics reported in the literature. ${ }^{93}$ On the other hand, a longlived radical dye cation is observed for an electrolyte free of redox couple (Figures $7 \mathrm{c}$ and S18). The geminate recombination takes place within $0.94 \mathrm{~ms}( \pm 0.02 \mathrm{~ms})$ and does not totally decay even beyond the technical limit of the $5 \mathrm{~ms}$ time scale of the streak camera. Based on these results, we can conclude that dye regeneration yield is close to being quantitative and does not constitute the step limiting the IPCE, i.e. $\Phi_{\text {reg }}>98 \%$ in $\mathrm{I}_{3}^{-} / \mathrm{I}^{-}$and $\Phi_{\text {reg }}>90 \%$ in $\mathrm{Co}(\mathrm{bpy})_{3}^{3+/ 2+}$.

The femtosecond dynamics of the excited state of VG20-C 16 has also been investigated. Figure 9a shows the differential absorption spectra obtained in an average-representing data set characteristic for $\mathrm{TiO}_{2}$ devices. The transient absorption kinetics are presented for selected wavelengths in Figure S19. These spectra are characterized by a prominent ESA peaking at $580 \mathrm{~nm}$, which, unlike the data obtained in solution, decays rapidly within 25 ps leaving behind a broad, red-shifted absorption with a maximum at $660 \mathrm{~nm}$ and a long tail spanning the visible part of the spectrum (cf. 100 ps delay). Such a residual long-lived signature is assigned to the absorption of the VG20- $\mathrm{C}_{16}$ radical cation $\left(\mathrm{VG} 20^{+}\right.$) in good agreement with the transient spectra measured using the picosecond TAS experiment (Figures 7 and S16).

In the near-IR part, SE is observed in the $850-1030 \mathrm{~nm}$ range, which decays on a picosecond time scale up to $25 \mathrm{ps}$. The GSB signal, between 730 and $900 \mathrm{~nm}$, shows a double peak structure, akin to the steady-state absorption spectra due to monomers and aggregates. According to the ground state absorption spectra (SSA) of $\mathrm{VG} 20-\mathrm{C}_{16}$ in solution and on $\mathrm{TiO}_{2}$ (Figures $2 \mathrm{~b}$ and S7), one infers that the high-energy band at $770 \mathrm{~nm}$ is dominated by aggregates, while the low-energy band is a combination of GSB bleach of monomers and aggregates and SE from monomers. The $880 \mathrm{~nm}$ band has decayed by half its amplitude within 10 ps and reaches a stable level of $\approx 20 \%$ of the initial value by 100 ps. While the fast decay is due to SE decay and partial ground state recovery, the long-time asymptote is due to the radical dye cation.

The $770 \mathrm{~nm}$ band shows different kinetics. A small rise of this aggregate-dominated band is observed until 2 ps (Figure S19), which is a clear signature of excitation of aggregates due 

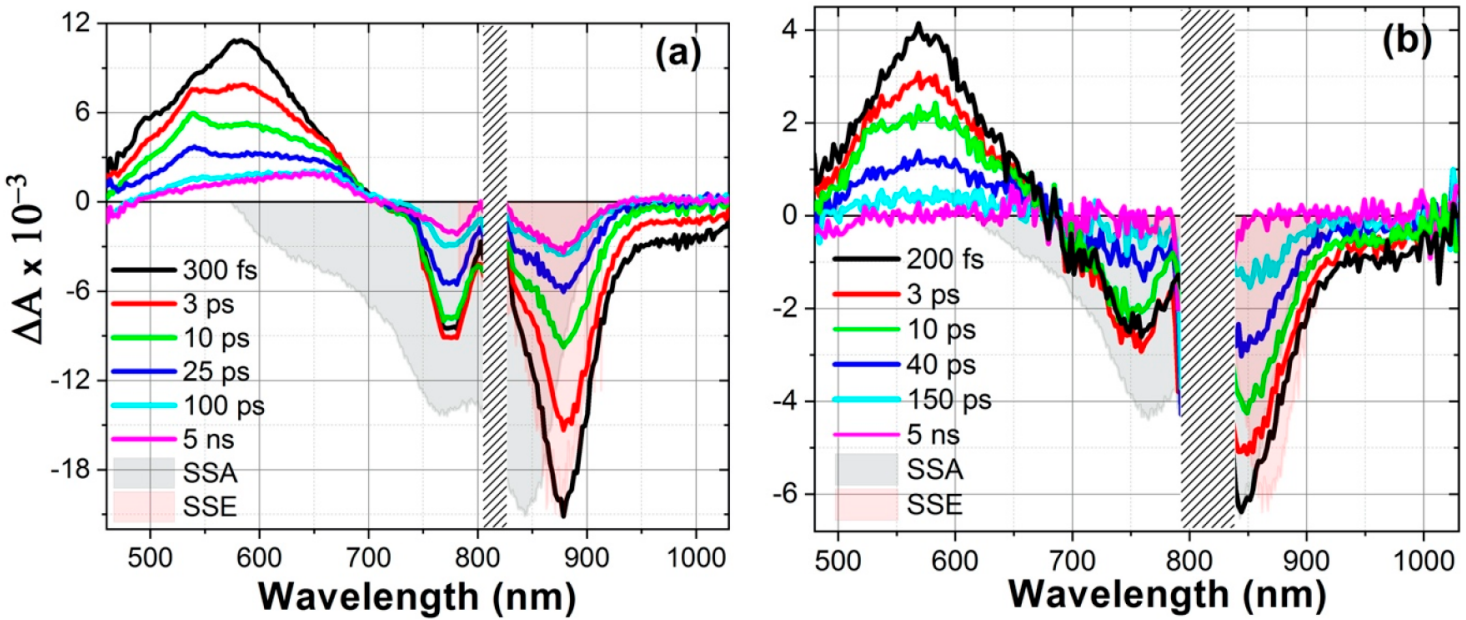

Figure 9. Transient spectra of $\mathrm{VG}_{20}-\mathrm{C}_{16}$ dye anchored on (a) injecting $\mathrm{TiO}_{2}$ nanocrystals and (b) noninjecting $\mathrm{ZrO}_{2}$ nanocrystals. The devices were pumped at $800 \mathrm{~nm}$ with an energy of $90 \mu \mathrm{J} / \mathrm{cm}^{2}$. The electrolyte is composed of $1 \mathrm{~mol} / \mathrm{L} \mathrm{DMII}, 30 \mathrm{mmol} / \mathrm{L} \mathrm{I} \mathrm{I}_{2}$ and $1 \mathrm{~mol} / \mathrm{L} \mathrm{LiI} \mathrm{in}$ acetonitrile. SSA and SSE are steady-state absorption and emission spectra arbitrarily scaled for comparison and allow identification of the regions where ground state bleach (GSB) and stimulated emission (SE) dominate the signal. The SSE spectrum is available only for $\lambda<920 \mathrm{~nm}$, due to the limited sensitivity of the fluorimeter used.
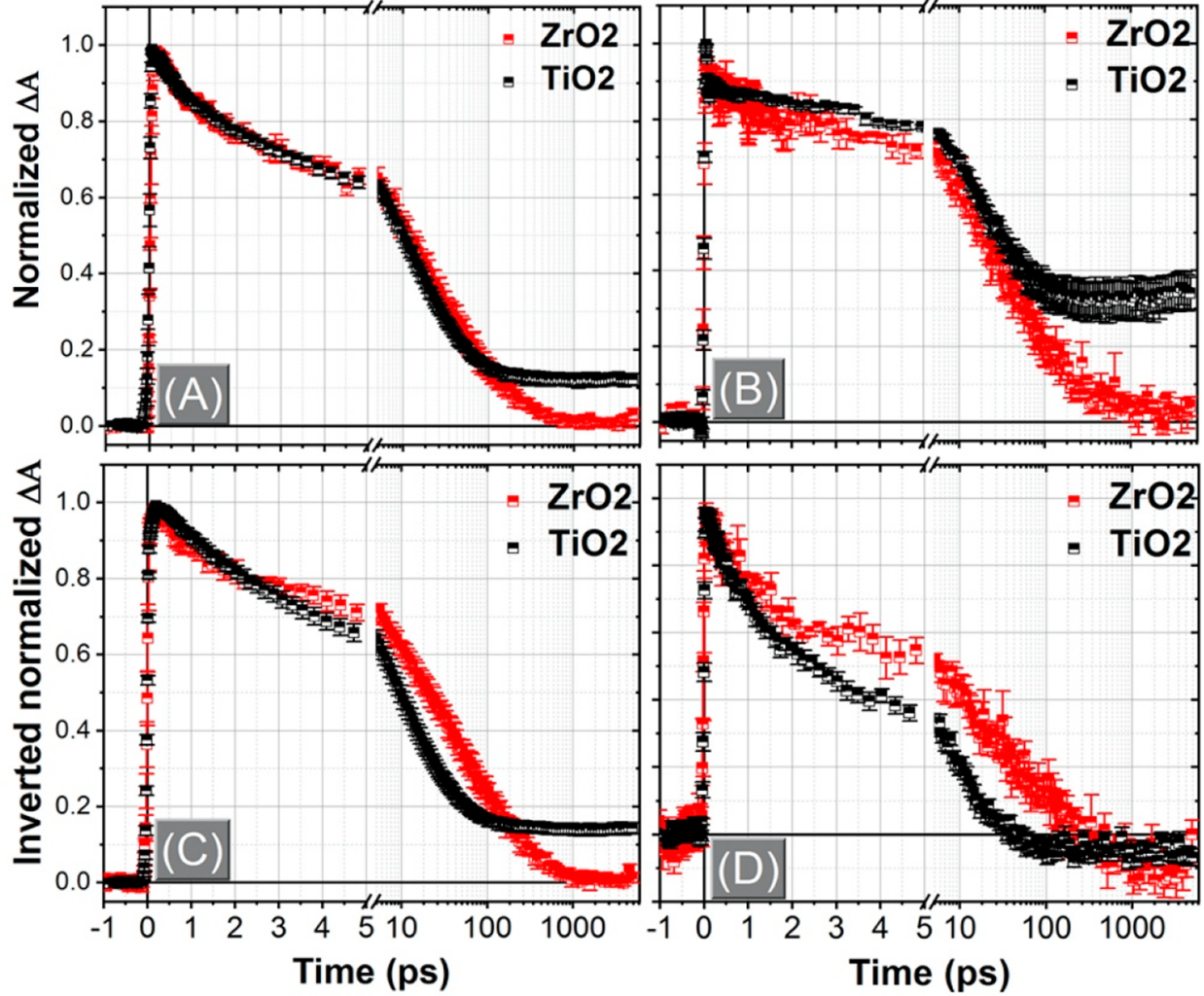

Figure 10. Comparison of normalized transient absorption kinetic profiles for the $\mathrm{VG} 20-\mathrm{C}_{16}$-based DSSC using either $\mathrm{ZrO}_{2}$ or TiO${ }_{2}$ nanocrystals at (a) $570 \mathrm{~nm}\left(\mathrm{ZrO}_{2}\right)$ and $585 \mathrm{~nm}\left(\mathrm{TiO}_{2}\right)$, (b) $640 \mathrm{~nm}\left(\mathrm{ZrO}_{2}\right)$ and $650 \mathrm{~nm}\left(\mathrm{TiO}_{2}\right)$, (c) $860 \mathrm{~nm}\left(\mathrm{ZrO}_{2}\right)$ and $880 \mathrm{~nm}\left(\mathrm{TiO}_{2}\right)$, and (d) $960 \mathrm{~nm}(\mathrm{ZrO})_{2}$ and $975 \mathrm{~nm}\left(\mathrm{TiO}_{2}\right)$. All DSSC devices were excited at $800 \mathrm{~nm}$ with $90 \mu \mathrm{J} / \mathrm{cm}^{2}$. The kinetics are averaged over seven samples for TiO $\mathrm{T}_{2}$ and three samples for $\mathrm{ZrO}_{2}$. Error bars indicate the statistical standard error.

to energy transfer (ET) from monomers. In addition, a sharp absorption feature develops at $\lambda \approx 535 \mathrm{~nm}$ on a 2 ps time scale. Since it is not observed in monomers, it is attributed to ESA of aggregates, rising according to the monomer-aggregate energy transfer process.

If all molecules (monomers and aggregates) became photooxidized, and since the cation absorption is negligible in the region of dominant GSB (800-900 nm), the negative $\Delta A$ signal should not decay with time, contrary to what is herein observed, meaning that the carrier injection yield $\left(\Phi_{\text {inj }}\right)$ is wellbelow $100 \%$. Hence, the ratio $\operatorname{GSB}(t=0.2 \mathrm{ps}) / \mathrm{GSB}(t=5 \mathrm{~ns})$ provides an estimate of $\Phi_{\text {inj. }}$. However, part of $\Delta A$ is due to SE, thus making the determination of the pure GSB component difficult. Nevertheless, analyzing the $\Delta A(t=0) / \Delta A(t=5 \mathrm{~ns})$ ratio at different wavelengths $(770-850 \mathrm{~nm})$ provides an upper limit of $\Phi_{\text {inj }} \approx 30-35 \%$. Although lower, this value is 

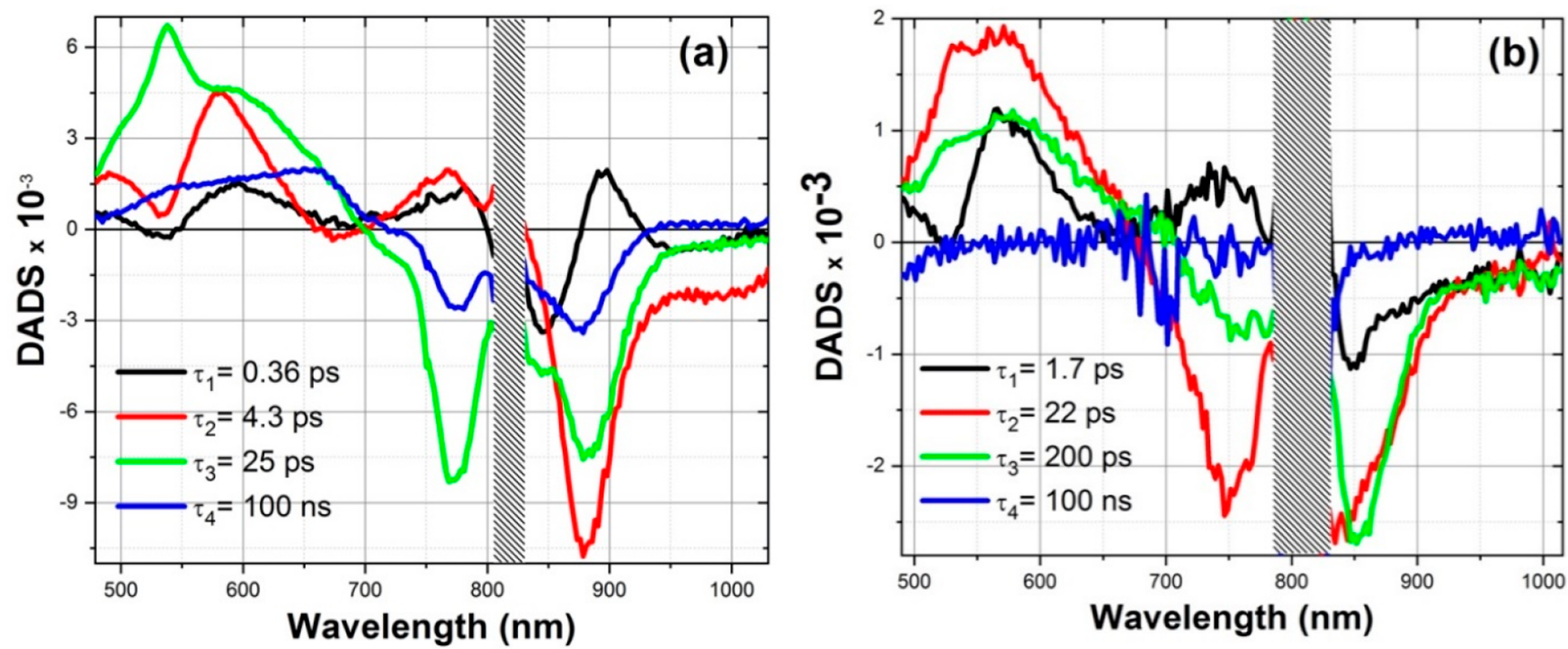

Figure 11. Wavelength-dependent amplitudes of $\mathrm{VG} 20-\mathrm{C}_{16}$-based devices including (a) injecting $\mathrm{TiO}_{2}$ nanocrystals and (b) noninjecting $\mathrm{ZrO} \mathrm{O}_{2}$ nanocrystals. The devices were pumped at $800 \mathrm{~nm}$ with an energy of $90 \mu \mathrm{J} / \mathrm{cm}^{2}$. The electrolyte is composed of $1 \mathrm{~mol} / \mathrm{L} \mathrm{DMII}, 30 \mathrm{mmol} / \mathrm{L} \mathrm{I}{ }_{2}$, and $1 \mathrm{~mol} / \mathrm{L} \mathrm{LiI} \mathrm{in} \mathrm{acetonitrile}$

relatively consistent with the IPCE at $810 \mathrm{~nm}(\approx 40-45 \%)$ (Figure $3 b$ ). The discrepancy is explained first by the TAS experimental conditions which are different than those of the IPCE and $J-V$ experiments in terms of excitation power (i.e. nonlinear response of DSSCs between cell photocurrent and incident light power) and the absence of a scattering layer in the device made for TAS measurements.

We have also studied the excited state dynamics in noninjecting $\mathrm{ZrO}_{2}$-based devices, which serve as a reference to identify excited state processes, e.g. energy transfer which may be in kinetic competition with the electron injection in $\mathrm{TiO}_{2}$ devices with an equivalent degree of aggregation. The differential spectra for $\mathrm{ZrO}_{2}$-based devices show clear differences compared with $\mathrm{TiO}_{2}$ (Figure 9b). Indeed, the radical cation signature is absent and the GSB fully recovers (zero signal) by ca. $1 \mathrm{~ns}$. The SE (>900 nm) decays slower than in $\mathrm{TiO}_{2}$ devices, since a weak signature can still be observed at a delay of 150 ps. The monomer-to-aggregate energy transfer (ET) is also observed for $\mathrm{ZrO}_{2}$, as a small increase of the bleach band at $760 \mathrm{~nm}$. Plots of kinetic traces and detailed multiexponential fits are gathered in Figures S19-21.

In order to highlight the carrier injection processes and their kinetics, Figure 10 shows kinetic traces obtained by averaging seven $\mathrm{TiO}_{2}$-based and three $\mathrm{ZrO}_{2}$-based devices. Selected wavelengths represent the monomer ESA (A), dye radical cation absorption (B), the low-energy GSB band (C), and SE (D). The prominent long-time signal for $\mathrm{TiO}_{2}$ is due to the VG20- $\mathrm{C}_{16}$ radical cation absorption $(580$ and $650 \mathrm{~nm}$ ) and incomplete GSB recovery $(880 \mathrm{~nm})$. Note a small positive absorption in the $\mathrm{SE}$ trace of $\mathrm{TiO}_{2}(\lambda \approx 975 \mathrm{~nm})$ most likely due to absorption by free carriers in $\mathrm{TiO}_{2}$ or to a near-IR tail of the radical cation absorption.

The data suggest two distinct reaction scenarios for VG20$\mathrm{C}_{16}$ on $\mathrm{TiO}_{2}$ and $\mathrm{ZrO}_{2}$, as summarized in Scheme S1 starting from photoexcited monomers (VG20*) and aggregates (Agg*).

As summarized in Tables $\mathrm{S6}-\mathrm{S} 7$, characteristic lifetimes for $\mathrm{TiO}_{2}$ are in the $0.5-1,4-8$, and $20-40$ ps range, in addition to a fixed $100 \mathrm{~ns}$ time accounting for the nondecaying signals at long delays. In order to identify the most relevant characteristic lifetimes and processes, a global fit approach was carried out, i.e. the wavelength-dependent decay times are approximated by four wavelength-independent values. For $\mathrm{TiO}_{2}$ (Figure 11a), the global decay constants obtained are 0.4 ps, $4.3 \mathrm{ps}, 25 \mathrm{ps}$, and $100 \mathrm{~ns}$, this latter value being fixed for the fit. Special features in the decay-associated difference spectra (DADS) allow identifying the main excited state processes, i.e. monomer-to-aggregate energy transfer and carrier injection/ radical cation formation and their respective lifetimes. For the former, and as discussed above, the rise of the $770 \mathrm{~nm} \mathrm{GSB}$ band and the $530 \mathrm{~nm}$ aggregate-ESA peak are the fingerprint, reflected in the DADS with dominating positive and negative signals, respectively. Hence, the energy transfer with rate $k_{\mathrm{ET}}$ is operative during the subpicosecond (0.4 ps) and the $\approx 4 \mathrm{ps}$ phases (Figure 11a). Charge injection/radical cation formation is best identified as a rise of the absorption at the radical cation peak wavelength $(660-670 \mathrm{~nm})$ and monomer excited state decay, i.e. the decay of SE $(>950 \mathrm{~nm})$. The DADS of Figure 11 a shows that charge injection, rate $k_{\text {inj }}$, occurs concomitantly with the energy transfer, dominantly during the $\approx 4$ ps time scale and to a lesser extent at shorter times (0.4 ps DADS). The 25 ps DADS is characterized by SE and ESA decay both for monomers and aggregates (peak at $530 \mathrm{~nm}$ ), but these decay amplitudes hide possibly weaker signatures of radical cation formation since the $25 \mathrm{ps}$ DADS at $660 \mathrm{~nm}$ is purely positive (i.e., ESA decay).

The same global analysis on $\mathrm{ZrO}_{2}$ is reported in Figure $11 \mathrm{~b}$. It reveals four time constants: $1.7,22$, and $200 \mathrm{ps}$ in addition to a long-lived but almost vanishing $100 \mathrm{~ns}$, used for consistency with fits of the $\mathrm{TiO}_{2}$ data, its amplitude being in the noise level. The fastest 1.7 ps component (black line) displays a DADS very similar to that of $\mathrm{TiO}_{2}$, with all the features consistent with monomer-to-aggregate energy transfer $\left(k_{\mathrm{ET}}\right)$. The ca. 24 ps component (red curve) displays signatures of both monomer and aggregate excited state decay: monomer SE > $850 \mathrm{~nm}$, monomer and aggregate ESA decay $(450-680 \mathrm{~nm})$, with the weak sharp feature at $530 \mathrm{~nm}$ already identified for $\mathrm{TiO}_{2}$ as due to aggregate ESA $\left(k_{\mathrm{agg}}\right)$. Note that the fast sub-10 
ps component observed for electron injection (DADS negative at $660-680 \mathrm{~nm}$ ) is absent as expected. Remarkably, the longer $\approx 200$ ps component (blue curve) is due to a second slower monomer excited state decay $\left(k_{\mathrm{nr}}\right)$, since it displays SE, ESA, and GSB recovery very similarly, although with a shorter lifetime, to VG20- $\mathrm{C}_{16}$ in solution (Figure 2).

In summary, the comparison of $\mathrm{VG} 20-\mathrm{C}_{16}$ on $\mathrm{TiO}_{2}$ and $\mathrm{ZrO}_{2}$ allows to identify the kinetic signatures of electron injection within dominantly 4 ps most probably from monomers $\left(k_{\text {inj }}\right)$, competing with monomer-to-aggregate energy transfer $\left(k_{\mathrm{ET}}\right)$ identified already on a 0.4 ps time scale, but also on the slower 4 ps lifetime (Table 3 ). This

Table 3. Average Lifetimes Characterizing the Main Photophysical Processes for VG20- $\mathrm{C}_{16}$ on $\mathrm{ZrO}_{2}$ and $\mathrm{TiO}_{2}$ DSSCs Obtained from Femtosecond Transient Absorption Studies ${ }^{a}$

$\begin{array}{ccccc}\mathrm{VG} 20-\mathrm{C}_{16} \text { DSSCs } & \tau_{1}(\mathrm{ps}) & \tau_{2}(\mathrm{ps}) & \tau_{3}(\mathrm{ps}) & \tau_{4}(\mathrm{~ns}) \\ \mathrm{TiO}_{2}+50 \mathrm{mM} \mathrm{CDCA} & 0.4 & 4.3 & 25 & 100 \\ \mathrm{ZrO}_{2}+50 \mathrm{mM} \mathrm{CDCA} & 1.7 & 22 & 200 & 100\end{array}$

${ }^{a} \tau_{1}$ is dominated by monomer-to-aggregate energy transfer. For $\mathrm{TiO}_{2}$ devices, electron injection occurs on both the $\tau_{1}$ and $\tau_{2}$ time scales.

kinetic competition limits the electron injection efficiency from the monomer to ca. $30 \%$. Injection from the monomers and aggregates may also take place on the 25 ps time scale since prominent excited state decay is observed, but a clear radical cation formation signature is missing possibly due to compensating for ESA decay/radical cation formation. Based on all of these important results, we can clearly confirm that aggregate formation and the related energy transfer from monomer to the aggregates limits the injection efficiency and the performances of this type of NIR-DSSC using polymethine cyanine dyes.

\section{CONCLUSIONS}

In this work, a family of NIR-selective polymethine cyanine dyes coded as VG20- $\mathrm{C}_{x}$ was developed. The main attribute of VG20- $C_{x}$ is its strong and sharp $S_{0}-S_{1}$ transition in the nearinfrared region $(\lambda=832 \mathrm{~nm})$ and a minimized $S_{0}-S_{n}$ contribution in the far blue where the human retina is poorly sensitive. By bringing the NIR-selective dye-sensitized solar cell transmittance in the maximum region of the photopic response, we herein demonstrated a never reached level of aesthetic performance with an AVT value of $76 \%$, CRI of $92.1 \%$, and CCT of $4223 \mathrm{~K}$ when associated with Co(bpy) $3^{3+/ 2+}$ redox mediator in the electrolyte.
After a carefully led optimization of the dye structure and all device fabrication parameters, we demonstrated a PCE as high as $3.1 \%$ under A.M. $1.5 \mathrm{G}$ conditions. As a result of the absorber bandgap narrowing, making less overpotential for both injection and dye regeneration, we revealed that the electron injection is in kinetic competition with nonproductive monomer-to-aggregate energy transfer which limits the device performance based on such polymethine cyanine dyes. ${ }^{43,94}$ Nevertheless, this first proof-of-concept of selective NIR-dyesensitized solar cells opens up new scientific and technological directions for the field of transparent PVs filling the gap between organic photovoltaic (OPV) having high performances with relatively lower AVT in the range of $50 \%$ and LSC reaching above $80 \%$ AVT but with very poor performances. Based on this first work, we estimate that NIR-DSSCs can reach (i) AVT values greater than $80 \%$ by developing more transparent redox mediators and by abating molecular aggregation in the SAM and (ii) power conversion efficiencies greater than $7 \%$ can rapidly obtained after a complete redesign of all the DSSC components to reduce internal energy losses during the photon-to-electron conversion and once again by limiting the formation of harmful aggregates in the SAM thus turning the unproductive monomer-to-aggregate energy transfer into useful electron injection from reactive monomer excited states.

\section{EXPERIMENTAL SECTION}

The synthetic procedure to obtain the symmetrical heptamethine cyanine dyes, VG20, is reported in Scheme 1. It involves the condensation of the quaternary heterocyclic salts (2), bearing an activated methyl group, with the Vilsmeier-Haack reagent $3{ }^{95}$

The 1,1,2-trimethyl- $1 H$-benzo[e]indole-7-carboxylic acid (1) was readily obtained exploiting the Fischer indole synthesis, as previously described. ${ }^{96}$ The subsequent quaternization of the benzoindolenine ring, performed under microwave irradiation, ${ }^{97}$ led to increased acidity of the methyl group which enabled the cyanine bridge formation (see the first step in Scheme 1). All the symmetrical cyanine dyes were synthesized in a one-step reaction under microwave heating by reacting 2 equiv of quaternary heterocyclic salts 2 with the Vilsmeier-Haack reagent 3 in the presence of potassium acetate and ethanol (see Scheme 1). The brownish solid in the reaction mixture was filtered and washed with diethyl ether. Unreacted potassium acetate crystals were then removed by DCM. Finally, a recrystallization in acetonitrile was performed, and once all the precipitate was dissolved, a few drops of acetic acid were added to completely protonate the carboxylic moieties.

All microwave reactions were performed in a single-mode Biotage Initiator 2.5. TLC was performed on silica gel 60 F254 plates. GC-MS spectra were recorded on a Thermo Finnigan Trace GC with a crosslinked methyl silicone capillary column, coupled to a Thermo

\section{Scheme 1. Synthesis of the VG20 Cyanine Series ${ }^{a}$}
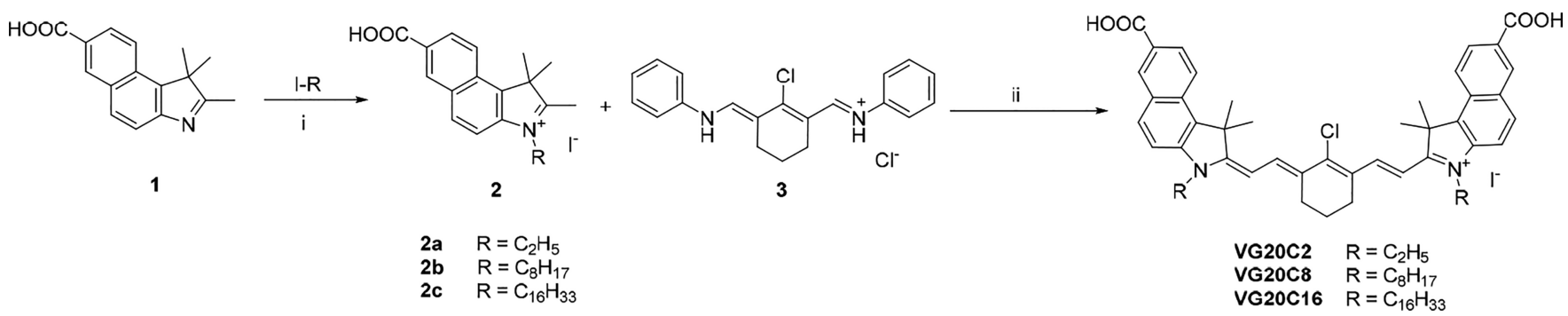

${ }^{a}$ Experimental conditions: (i) anhydrous acetonitrile, iodoalkane, MW, $40 \mathrm{~min}, 155^{\circ} \mathrm{C}$; (ii) potassium acetate, absolute ethanol, $\mathrm{MW}, 10 \mathrm{~min}, 120$ ${ }^{\circ} \mathrm{C}$. 
Finnigan Trace MS mass spectrometer equipped with an electronic impact source (EI). UV-visible absorption spectra were recorded on a Shimadzu UV-1700 spectrometer. ${ }^{1} \mathrm{H}$ NMR spectra were recorded on a Jeol ECZR $600 \mathrm{MHz}$ NMR. The purity of the final compounds was evaluated through HPLC using a Shimadzu LC $10 \mathrm{AD}$ equipped with a C18 Altech $\mathrm{C} 18250 \times 4$. Each VG20 dye was dissolved in methanol and $20 \mu \mathrm{L}$ of the solution was injected. The mobile phase (water/methanol) was used in gradient concentration: 80-20 at time $0 \mathrm{~min}, 80-20$ at time $5 \mathrm{~min}, 0-100$ at time $20 \mathrm{~min}$, and $0-100$ at time $30 \mathrm{~min}$. It was pumped at a flow rate of $1 \mathrm{~mL} / \mathrm{min}$. The temperature of the column was set at $35^{\circ} \mathrm{C}$. The UV detector was set at the maximum absorbance wavelength of the sample.

All the chemicals were purchased from Sigma-Aldrich, except for the Vilsmeier-Haack reagent 3 which was obtained from Cyanine Technologies and was used without any further purification. The intermediate 1,1,2-trimethyl-1H-benzo[e] indole-7-carboxylic acid was prepared as described in the literature. The 7-carboxy-1,1,2-trimethyl$1 H$-benzo[e]indol-3-ium salts $\mathbf{2} \mathbf{a}$ and $\mathbf{2} \mathbf{b}$ are known compounds and were prepared as reported in the literature. ${ }^{95,96}$ The carboxy- $1 H$ benzo[e]indol-3-ium salt $2 \mathrm{c}$ was synthesized according to the previously reported method. ${ }^{97}$

\section{Synthesis of \\ 7-Carboxy-1,1,2-trimethyl-3-hexadecyl-1H-benzo[e]- indol-3-ium lodide 2c}

1,1,2-Trimethyl-1H-benzo[e]indole-7-carboxylic 1 ( $1 \mathrm{~g}, 3.95 \mathrm{mmol})$, 1-iodohexadecane $(4.97 \mathrm{~mL}, 5.57 \mathrm{~g}, 15.8 \mathrm{mmol})$, and $8 \mathrm{~mL}$ of $\mathrm{CH}_{3} \mathrm{CN}$ were introduced in a $10-20 \mathrm{~mL}$ microwave reaction vial. The reaction is carried out at $155{ }^{\circ} \mathrm{C}$ for $40 \mathrm{~min}$ under microwave irradiation. The resulting mixture was evaporated under vacuum, and the raw material was repeatedly washed under stirring with diethyl ether $(3 \times 100 \mathrm{~mL})$, filtered, and then crystallized with acetonitrile. $2 \mathrm{c}$ was obtained as a yellow powder $(50 \mathrm{mg}, 21 \%)$.

${ }^{1} \mathrm{H}$ NMR $\left(600 \mathrm{MHz}, \mathrm{DMSO}-\mathrm{d}_{6}\right) \delta 8.88(\mathrm{~d}, J=1.7 \mathrm{~Hz}, 1 \mathrm{H}), 8.50$ (dd, $J=16.9,8.9 \mathrm{~Hz}, 2 \mathrm{H}), 8.24(\mathrm{~d}, J=9.0 \mathrm{~Hz}, 1 \mathrm{H}), 8.20(\mathrm{dd}, J=8.8$, $1.8 \mathrm{~Hz}, 1 \mathrm{H}), 4.57(\mathrm{t}, J=7.8 \mathrm{~Hz}, 2 \mathrm{H}), 2.96(\mathrm{~s}, 3 \mathrm{H}), 1.88(\mathrm{p}, J=7.9$ $\mathrm{Hz}, 2 \mathrm{H}), 1.77(\mathrm{~s}, 6 \mathrm{H}), 1.27-1.14(\mathrm{~m}, 26 \mathrm{H}), 0.84(\mathrm{t}, J=7.0 \mathrm{~Hz}, 3 \mathrm{H})$. ESI $\left[\mathrm{M}^{+}\right]: 478.34 \mathrm{~m} / z$.

ESI $[\mathrm{M}-\mathrm{I}-\mathrm{M}]^{+}: 1082.54 \mathrm{~m} / \mathrm{z}$.

\section{General Synthetic Procedure of VG20 Dyes}

7-Carboxy-1,1,2-trimethyl-1H-benzo[e]indol-3-ium salt 2, VilsmeierHaack reagent 3, and potassium acetate in a 2:1:2 ratio were introduced with absolute ethanol in a microwave reaction vial. The reaction was carried out at $120{ }^{\circ} \mathrm{C}$ for $10 \mathrm{~min}$ under microwave irradiation until TLC and UV showed reaction completion. At the end of the reaction a brownish precipitate and a dark green solution was observed. The precipitate was then filtered and washed with diethyl ether. The crude was dissolved in dichloromethane to remove the potassium acetate. Then, a recrystallization was performed with acetonitrile and a few drops of acetic acid were added. The precipitate was then filtered and washed several times with diethyl ether to obtain a dark powder.

\section{VG20-C}

7-Carboxy-3-ethyl-1,1,2-trimethyl-1H-benzo[e]indol-3-ium iodide 2a $(500 \mathrm{mg}, 1.22 \mathrm{mmol})$, Vilsmeier-Haack reagent $3(176 \mathrm{mg}, 0.49$ $\mathrm{mmol}$ ), potassium acetate (119 $\mathrm{mg}, 1.22 \mathrm{mmol}$ ), and $5 \mathrm{~mL}$ of absolute ethanol were reacted as described in the general procedure. VG20- $\mathrm{C}_{2}$ was obtained as a bronze precipitate $(81 \mathrm{mg}, 20 \%)$.

MS (ESI) $m / z$ calculated for $[\mathrm{M}-\mathrm{I}]^{+} 699.2984$, found 699.30 .

${ }^{1} \mathrm{H}$ NMR $\left(600 \mathrm{MHz}, \mathrm{DMSO}-\mathrm{d}_{6}\right): \delta 8.73(\mathrm{~s}, 2 \mathrm{H}), 8.41-8.38(\mathrm{~m}$, $4 \mathrm{H}), 8.33(\mathrm{~d}, J=6 \mathrm{~Hz}, 2 \mathrm{H}), 8.10(\mathrm{dd}, J=6 \mathrm{~Hz}, J=1.68 \mathrm{~Hz}, 2 \mathrm{H})$, $7.88(\mathrm{~d}, J=6,2 \mathrm{H}), 6.43(\mathrm{~d}, J=18 \mathrm{~Hz}, 2 \mathrm{H}), 4.41(\mathrm{~m}, 4 \mathrm{H}), 2.78(\mathrm{~m}$, $4 \mathrm{H}), 1.96(\mathrm{~s}, 12 \mathrm{H}), 1.91(\mathrm{~m}, 2 \mathrm{H}), 1.37(\mathrm{t}, J=6 \mathrm{~Hz}, 6 \mathrm{H})$.

The compound solubility was too low to record a ${ }^{13} \mathrm{C}$ NMR spectrum.

$\lambda_{\max }=825 \mathrm{~nm}, \lambda_{\mathrm{em}}=839 \mathrm{~nm}, \varepsilon=118000 \mathrm{1} / \mathrm{M} \cdot \mathrm{cm}$ (measured in absolute ethanol).

\section{VG20-C 8}

7-Carboxy-1,1,2-trimethyl-3-octyl-1H-benzo[e]indol-3-ium iodide $\mathbf{2 b}$ $(500 \mathrm{mg}, 1.01 \mathrm{mmol}), \mathrm{N}-(((E)-2-$ chloro-3-((phenylamino)methylene)cyclohex-1-en-1-yl)methylene)benzenaminium chloride 3 $(145 \mathrm{mg}, 0.40 \mathrm{mmol})$, potassium acetate $(99 \mathrm{mg}, 1.01 \mathrm{mmol})$, and absolute ethanol $(5 \mathrm{~mL})$ were introduced in a microwave vial and reacted as described in the general procedure.

MS (ESI) $m / z$ calculated for $[\mathrm{M}-\mathrm{I}]^{+} 867.4862$, found 867.57 .

The final compound VG20-C $\mathrm{C}_{8}$ was obtained as a brown-dark red solid (223 mg, 56\%).

${ }^{1} \mathrm{H}$ NMR (600 MHz, DMSO-d 6 ): $\delta 8.72(\mathrm{~s}, 2 \mathrm{H}), 8.38(\mathrm{~d}, J=12$ $\mathrm{Hz}, 4 \mathrm{H}), 8.31$ (d, $J=6 \mathrm{~Hz}, 2 \mathrm{H}), 8.10(\mathrm{~d}, J=6 \mathrm{~Hz}, 2 \mathrm{H}), 7.87$ (d, $J=6$ $\mathrm{Hz}, 2 \mathrm{H}), 6.41(\mathrm{~d}, J=12 \mathrm{~Hz}, 2 \mathrm{H}), 4.36(\mathrm{~m}, 4 \mathrm{H}), 2.78(\mathrm{~m}, 4 \mathrm{H}), 1.96$ $(\mathrm{s}, 12 \mathrm{H}), 1.89(\mathrm{~m}, 2 \mathrm{H}), 1.79(\mathrm{~m}, 4 \mathrm{H}), 1.41(\mathrm{~m}, 4 \mathrm{H}), 1.34(\mathrm{~m}, 4 \mathrm{H})$, $1.24(\mathrm{~m}, 12 \mathrm{H}), 0.83(\mathrm{t}, J=6 \mathrm{~Hz}, 6 \mathrm{H})$.

The compound solubility was too low to record a ${ }^{13} \mathrm{C} N M R$ spectrum.

$\lambda_{\max }=829 \mathrm{~nm}, \lambda_{\mathrm{em}}=845 \mathrm{~nm}, \varepsilon=1360001 / \mathrm{M} \cdot \mathrm{cm}$ (measured in absolute ethanol).

\section{VG20-C 16}

7-Carboxy-3-hexadecyl-1,1,2-trimethyl-1H-benzo[e]indol-3-ium iodide 2c (500 mg, $0.82 \mathrm{mmol}$ ), Vilsmeier-Haack reagent 3 (119 $\mathrm{mg}, 0.33 \mathrm{mmol})$, potassium acetate $(81 \mathrm{mg}, 0.82 \mathrm{mmol})$, and $5 \mathrm{~mL}$ of absolute ethanol were reacted as described in the general procedure. A bronze precipitate was obtained (96 mg, yield: $24 \%$ ).

MS (ESI) $\mathrm{m} / z$ calculated for $[\mathrm{M}-\mathrm{I}]^{+} \mathrm{m} / z$ : 1091.7366, found 1091.695.

${ }^{1} \mathrm{H}$ NMR (600 MHz, DMSO) $\delta 8.69(\mathrm{~s}, 2 \mathrm{H}), 8.40(\mathrm{~d}, J=12 \mathrm{~Hz}$, $2 \mathrm{H}), 8.32(\mathrm{~d}, J=6 \mathrm{~Hz}, 2 \mathrm{H}), 8.24(\mathrm{~d}, J=6 \mathrm{~Hz}, 2 \mathrm{H}), 8.09(\mathrm{dd}, J=12$ $\mathrm{Hz}, 2 \mathrm{H}), 7.79(\mathrm{~d}, J=6 \mathrm{~Hz}, 2 \mathrm{H}), 6.36(\mathrm{~d}, J=12 \mathrm{~Hz}, 2 \mathrm{H}), 4.32(\mathrm{t}, J=$ $6 \mathrm{~Hz}, 4 \mathrm{H}), 2.72(\mathrm{~m}, 4 \mathrm{H}), 1.95(\mathrm{~s}, 12 \mathrm{H}), 1.89(\mathrm{~m}, 2 \mathrm{H}) 1.79(\mathrm{~m}, 4 \mathrm{H})$, $1.39(\mathrm{~m}, 4 \mathrm{H}), 1.32(\mathrm{~m}, 4 \mathrm{H}), 1.16(\mathrm{~m}, 42 \mathrm{H}), 0.78(\mathrm{t}, J=6 \mathrm{~Hz}, 6 \mathrm{H})$.

The compound solubility was too low to record a ${ }^{13} \mathrm{C} N M R$ spectrum.

$\lambda_{\max }=831 \mathrm{~nm}, \lambda_{\mathrm{em}}=848 \mathrm{~nm}, \varepsilon=154000 \mathrm{M} \cdot \mathrm{cm}$ (measured in absolute ethanol).

\section{Determination of Molar Extinction Coefficient}

A concentrated solution of each dye was prepared by weighting the dye $(5-7 \mathrm{mg}$ ) and dissolving it into $10 \mathrm{~mL}$ of absolute ethanol $(\mathrm{EtOH})$. Three diluted solution $(25 \mathrm{~mL})$ of $\mathrm{EtOH}$ were prepared by taking aliquots $(0.2,0.1$, and $0.05 \mathrm{~mL})$ of the stock solution. The diluted solutions were measured by steady-state UV-visible absorption spectroscopy (Shimadzu UV-1700) using a quartz cuvette ( $1 \mathrm{~cm}$ pathway length). The absorbance intensities of each solution at the $\lambda_{\max }$ were plotted versus the sample concentration. A linear fit was applied to determine the molar extinction coefficient $(\varepsilon)$ using the Beer-Lambert equation. The analysis was duplicated. The obtained data were considered acceptable when the difference between the determined $\log \varepsilon$ was less or equal to 0.02 in respect to their average. Otherwise, new concentrated dye stock solution in absolute EtOH was prepared and the protocol repeated.

Materials. Dimethyl sulfoxide (DMSO), ethanol (EtOH), acetonitrile (ACN), chenodeoxycholic acid (CDCA), and lithium bis(trifuoromethanesulfonyl)imide (LiTFSI) were purchased from Sigma-Aldrich. Tris $\left(2,2^{\prime}\right.$-bipyridine)cobalt(II) di[bis(trifluoromethanesulfonyl)imide] and tris $\left(2,2^{\prime}\right.$-bipyridine $)$ cobalt(III) tris[bis(trifluoromethanesulfonyl)imide] were purchased from Dyenamo AB.

Fabrication of Solar Cells. The mesoporous $\mathrm{TiO}_{2}$ electrodes are prepared as previously described yielding $8 \mu \mathrm{m}$ thick transparent electrode. ${ }^{98}$ For the device performance it was sheltered with a $5 \mu \mathrm{m}$ thick $400 \mathrm{~nm}$-based $\mathrm{TiO}_{2}$ scattering layer. The fluorine-doped $\mathrm{SnO}_{2}$ (FTO) conducting glass (NSG-10, Nippon Sheet Glass) was thoroughly cleaned with a detergent solution, acetone, and ethanol solvents. The initial step was followed by an $18 \mathrm{~min}$ ultraviolet $/ \mathrm{O}_{3}$ treatment. Then the substrates were treated with $40 \mathrm{mM} \mathrm{TiCl}{ }_{4}$ aqueous solution at $70{ }^{\circ} \mathrm{C}$ for $45 \mathrm{~min}$ in order to make a thin and compact $\mathrm{TiO}_{2}$ underlayer. The colloidal $\mathrm{TiO}_{2}$ paste of Dyenamo DNEP03 was used in conjunction with tri-iodide/iodide redox couple 
and DSL30 NR-D (Greatcell Solar) with cobalt complexes. The layers were sequentially deposited on the $\mathrm{TiCl}_{4}$ solution-treated FTO glass via screen printing technology, which results in a different thickness of $\mathrm{TiO}_{2}$. The $\mathrm{TiO}_{2}$ film was sintered at $500{ }^{\circ} \mathrm{C}$ under dry air flow and cooled down to room temperature to a obtain mesoporous, electronic conductive film. The mesoporous $\mathrm{TiO}_{2}$ film was treated in $\mathrm{TiCl}_{4}(40$ $\mathrm{mmol} / \mathrm{L}$ ) and kept at $70{ }^{\circ} \mathrm{C}$ in an oven for $30 \mathrm{~min}$. After sintering at $500{ }^{\circ} \mathrm{C}$ in air and cooled down to $80{ }^{\circ} \mathrm{C}$, the mesoporous $\mathrm{TiO}_{2}$ electrodes were stained by immersing them into the dye solution at room temperature or $4{ }^{\circ} \mathrm{C}$ for $12 \mathrm{~h}$ and 7 days for experiments at -20 ${ }^{\circ} \mathrm{C}$. The $\mathrm{Ga}_{2} \mathrm{O}_{3}$ passivated mesoporous $\mathrm{TiO}_{2}$ electrodes were made according to prior literature. ${ }^{85}$ The growth rate of $\mathrm{Ga}_{2} \mathrm{O}_{3}$ was estimated to be $\sim 1 \AA$ per cycle as deduced from ellipsometry on the $\mathrm{Si}$ wafer. The dye solution is composed of VG20-C 16 (100 $\mu \mathrm{mol} / \mathrm{L})$ and CDCA $(50 \mathrm{mmol} / \mathrm{L})$ in DMSO/EtOH $(1: 9, \mathrm{v} / \mathrm{v})$. The dyecoated $\mathrm{TiO}_{2}$ film working electrode and thermally low-concentrated platinized conducting glass counter electrode were assembled using a $25 \mu \mathrm{m}$ thick Surlyn hot-melt ring (DuPont, USA) heated at $125^{\circ} \mathrm{C}$. The internal space was filled with electrolyte using a vacuum pump through a predrilled hole on the counter electrode. The hole was sealed with a Bynel sheet and a thin glass cover by heating. All fabrication and assembling devices using the tri-iodide/iodide redox couple were carried out in a dry room (dew point of ca. $-75^{\circ} \mathrm{C}$ ). The $\mathrm{Co}(\mathrm{III} / \mathrm{II})$ tris(bipyridyl)-based redox electrolyte is made from tris $\left(2,2^{\prime}\right.$-bipyridine $)$ cobalt(II) di[bis(trifluoromethanesulfonyl)imide] $(0.25 \mathrm{~mol} / \mathrm{L})$, tris $\left(2,2^{\prime}\right.$-bipyridine $)$ cobalt(III) tris[bis(trifluoromethanesulfonyl)imide] $(0.05 \mathrm{~mol} / \mathrm{L})$, and LiTFSI (0.1, 0.5 , or 1.0 $\mathrm{mol} / \mathrm{L}$ ) in acetonitrile. All PCE values have been reproduced. The reproducibility over cells is in the range of $0.1 \%$ in power conversion efficiencies. W.N., F.G., and V.N. reproduced the 3.1\% PCE record.

Optical and Electrical Characterization of Solar Cells. During the photovoltaic performance measurements, a black metal mask with an aperture area of $0.158 \mathrm{~cm}^{2}$ covered the solar cells. The solar cells were measured under radiation at $100 \mathrm{~mW} / \mathrm{cm}^{2}$ provided by a $450 \mathrm{~W}$ xenon lamp of the Oriel solar simulator (USA). The spectral output of the lamp passed a Schott K113 Tempax sunlight filter (Präzisions Glas \& Optik GmbH, Germany) reducing the mismatch between the simulated and true solar spectra to less than $2 \%$. The light intensity was determined using a calibrated $\mathrm{Si}$ reference diode equipped with an infrared cutoff filter (KG-3, Schott). The $J-V$ curves were recorded by a Keithley 2400 source meter. The voltage scan rate was set to $20 \mathrm{mV} / \mathrm{s}$. IPCE spectra were measured with a lock-in amplifier (Stanford Research System SR830 DSP) under chopped monochromatic light $(2 \mathrm{~Hz})$ generated by a white light source from a $300 \mathrm{~W}$ xenon lamp passing through a Gemini-180 double monochromator (Jobin Yvon Ltd.). The optical properties of the dye in solution and in the device were measured using an Agilent Cary 5000 spectrophotometer. A quartz cuvette with $1 \mathrm{~cm}$ light path was used for solution in dual beam transmission mode. For devices, all measurements were carried out in total transmittance mode using a $150 \mathrm{~mm}$ integration sphere. Background and zero were corrected, however without subtracting any external contributions such as glass absorption and reflection. All AVT measurements therefore correspond to a complete device assessment. CRI and CCT values were determined accordingly to the literature. ${ }^{99,100}$

Picosecond Pump-Probe Transient Absorption Spectroscopy (TAS) Measurements. The picosecond setup for the TAS measurements was used to investigate regeneration and recombination kinetics of the dye radical cation. The setup is composed of (1) a Nd:YAG laser (EKSPLA, PL2550, $10 \mathrm{~Hz}$ repetition rate, 30 ps pulse duration, 532 or $355 \mathrm{~nm}$ excitation) in combination with an optical parametric generator (EKSPLA, PG400 with broad excitation range $420-2300 \mathrm{~nm}$ ) which is pumped by the third harmonic of Nd:YAG; (2) three different probe systems (Hamamatsu Photonics): Xe breakdown cell for the shortest $0.5-20$ ns time scale; Xe Flash lamp for the $50 \mathrm{~ns}$ to $2 \mu$ s time scale; and continuous $150 \mathrm{~W}$ Xe lamp for the $5 \mu$ s to $10 \mathrm{~ms}$ time scale; (3) detector part: spectrograph (Princeton Instruments, SP2300), high dynamic range streak camera (Hamamatsu Photonics, C13410) with digital readout camera (Hamamatsu Photonics, ORCA Flash4, C11440); (4) delay generator
(Stanford Research Systems, DG645), delay unit, and shutters control unit (Hamamatsu Photonics) to synchronize all the setup parts controlled by computer through the HPD-TA software (Hamamatsu Phonics); and (5) white light input optics, excitation optics, pump and probe shutters, moving sample holder, and motorized 12-position optical density filter wheel for attenuation of laser excitation pulse energy.

For the TAS measurements of the DSSC, the probe light was focused perpendicular to the sample and the pump light was focused $45^{\circ}$ to the sample. The probe light was attenuated with different optical density filters (Newport or Thorlabs) and transmitted through the sample. The resulting light was introduced into the spectrograph and analyzed by the streak camera. The energy of the pump pulse in the excitation wavelength range $810-830 \mathrm{~nm}$ was set to ca. $0.2 \mathrm{~mJ}$. A $750 \mathrm{~nm}$ short pass cutoff filter (Thorlabs) was placed before the spectrograph to cut scattering light from the pump. Transient absorption is calculated from four streak images according to the equation:

$$
\Delta A=-\log \left(\frac{\text { data }- \text { emission }}{\text { monitor }- \text { dark }}\right)
$$

where data is the intensity of the image obtained where both pump and probe are on, emission where only pump is on, monitor where only probe is on, and dark when both pump and probe are off in order to subtract the contribution of stray light. Each of these four images consisted of $N$ integrated camera images. Measurements are performed in the sequence, data, emission, monitor, dark, and this sequence is repeated $M$ times. In order to obtain a satisfactory signalto-noise ratio, $N$ was 500 and $M=5-10$.

Femtosecond Pump-Probe Transient Absorption Spectroscopy (TAS) Measurements. The experimental pump-probe setup was already described in detail in previous papers. ${ }^{101,102}$ To record the TA spectra, a home-built setup fs-TA spectrometer was utilized based on a Ti:sapphire regenerative amplifier laser system (Pulsar, Amplitude Technology) delivering 40 fs-long pulses, at 5 $\mathrm{kHz}$, centered at $800 \mathrm{~nm}$. One portion of the $800 \mathrm{~nm}$ beam is used directly as the pump beam, and the second for the white light generation $(460-1030 \mathrm{~nm})$ utilizing a $3 \mathrm{~mm}$ sapphire crystal. The residual fundamental at $800 \mathrm{~nm}$ was filtered by a conveniently concentrated solution of the IR125 dye (Lambda Physik) in EtOH in a $1 \mathrm{~mm}$ quartz cell. The relative linear polarization between pump and probe beams is set at the magic angle $\left(54.7^{\circ}\right)$, and the fwhm of the instrument response function (IRF) is $35 \mathrm{fs}$. To ensure sufficient reduction of the noise level, for every time point 200 spectra are averaged and the final data result from averaging 8 different scans in solution and 6-8 in the DSSC samples, changing the $2 \mathrm{~mm}$ long excitation line every 3-4 scans to avoid degradation. Every individual scan lasts $7 \mathrm{~min}$ and over $4-5$ scans no change of the kinetics is observed due to possible degradation. For solution samples, in order to avoid re-exciting the same molecules in the $0.5 \mathrm{~mm}$ quartz cuvette, we sufficiently circulate the sample using a peristaltic pump. The pump pulse intensity was set so as to ensure a linear dependence of the ground state bleach signals in all experiments reported here. A 90 $\mu \mathrm{J} / \mathrm{cm}^{2}$ pump energy fluence was used both on the solution samples, as well as on the complete DSSC samples. The DSSC samples for the TA measurements were prepared under similar conditions as described above, restricted on single- $\mathrm{TiO}_{2}$ or $\mathrm{ZrO}_{2}$ layers and sensitization was carried out overnight $(14 \mathrm{~h})$ using the same composition of the dye solution. The optical density (OD) of $\mathrm{TiO}_{2}$ DSSCs was $\sim 0.4$, and it was $\sim 0.2$ for $\mathrm{ZrO}_{2}$. The concentration of the solution sample was $5 \times 10^{-5} \mathrm{M}$ and the $\mathrm{OD} / \mathrm{mm}=0.75$.

Data are processed to correct the effects of group velocity dispersion (chirp) in the white light continuum and to subtract the nonlinear signal from the solvent and the presence of any delayindependent background. ${ }^{101,102}$ All transient spectra presented in this work are obtained by appending two data sets covering two adjacent spectral windows, from 460 to $1030 \mathrm{~nm}$. After chirp correction, the zero time-delay is defined with an error bar of $30 \mathrm{fs}$ over the entire observation spectral window. Single wavelength fits are made with 
ORIGIN (eq 1), and global analysis, with the GLOTARAN software. $^{103}$

$$
\Delta \mathrm{A}(\lambda, t)=\sum_{\mathrm{i}} A_{i}(\lambda) \mathrm{e}^{-t / \tau_{\mathrm{i}}} \otimes \mathrm{IRF}
$$

Time-Correlated Single Photon Counting Measurements. Excited state lifetimes were monitored using a time-correlated single photon counting (TCSPC) technique using an Edinburgh Instrument FLS980 spectrometer. The same spectrometer was used for steadystate measurements using a continuous Xe light source and double excitation/emission monochromator. TCSPC experiments were carried out using a $70 \mathrm{ps}$ width laser diode as an excitation source $\left(20 \mathrm{MHz}\right.$ repetition rate, $5 \mathrm{pJ} / \mathrm{cm}^{2}$ average energy, instrument response in the range of $90-100 \mathrm{ps}$ fwhm) and a microchannel plate photomultiplier tube (MCP-PMT) Hamamatsu detector set after the first emission monochromator. A $780 \mathrm{~nm}$ long pass filter was used in emission to reject light scattering from the glass of the device. The emission was monitored at $840 \mathrm{~nm}$ with a slit opening of $10 \mathrm{~nm}$ in the emission monochromator. The numerical analysis of the excited-state lifetime has been determined after reconvolution of the photoluminescence decay considering the instrumental response function (IRF). The PLQY was measured with an integration sphere based on indirect and direct method.

Note for Device Optimization. All PCEs presented in this work include a scattering layer of $5.5 \mu \mathrm{m}$ thickness in the device to determine the maximum power conversion efficiency which can be obtained for this type of dye (transparent layer thickness is $8 \mu \mathrm{m}$ ). Comparison with a scattering layer $\left(J_{\mathrm{sc}}=11.6 \mathrm{~mA} / \mathrm{cm}^{2}, V_{\mathrm{oc}}=359\right.$ $\mathrm{mV}, \mathrm{ff}=0.62, \mathrm{PCE}=2.6 \%)$ and without scattering layer $\left(J_{\mathrm{sc}}=9.7\right.$ $\mathrm{mA} / \mathrm{cm}^{2}, V_{\mathrm{oc}}=348 \mathrm{mV}, \mathrm{ff}=0.61, \mathrm{PCE}=2.1 \%$ ) provides the reader the information that the scattering layer enhances the photocurrent by ca. $2 \mathrm{~mA} / \mathrm{cm}^{2}$. Most of this additional current originates from an enhancement in the blue region for which the particles scatter the most. Scattering of the $\mathrm{TiO}_{2}$ particles decreases substantially beyond $800 \mathrm{~nm}$ in accordance with Mie scattering theory. The $J-V$ and IPCE

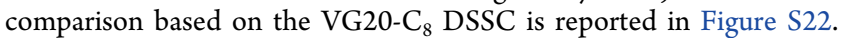

\section{ASSOCIATED CONTENT}

\section{Supporting Information}

The Supporting Information is available free of charge at https://pubs.acs.org/doi/10.1021/jacsau.1c00045.

Further UV-visible absorption spectroscopy experiments in solution and on mesoscopic $\mathrm{TiO}_{2}$ film, distribution of the molecular frontier orbitals, cyclic voltamperometry, additional PL and TA decays in solution or devices, additional $J-V$ curves under illumination, IPCE and IMVS/IMPS of NIR-DSSC devices, and tabulated values of additional results (PDF)

\section{AUTHOR INFORMATION}

\section{Corresponding Author}

Frédéric Sauvage - Laboratoire de Réactivité et Chimie des Solides, Université de Picardie Jules Verne (UPJV), CNRS UMR 7314, 80039 Amiens, France; (1) orcid.org/00000002-7740-3209; Email: frederic.sauvage@u-picardie.fr

\section{Authors}

Waad Naim - Laboratoire de Réactivité et Chimie des Solides, Université de Picardie Jules Verne (UPJV), CNRS UMR 7314, 80039 Amiens, France

Vittoria Novelli - Laboratoire de Réactivité et Chimie des Solides, Université de Picardie Jules Verne (UPJV), CNRS UMR 7314, 80039 Amiens, France

Ilias Nikolinakos - IPCMS, UMR 7504, 67034 Strasbourg, France
Nadia Barbero - Laboratoire de Réactivité et Chimie des Solides, Université de Picardie Jules Verne (UPJV), CNRS UMR 7314, 80039 Amiens, France; Department of Chemistry, NIS Interdepartmental and INSTM Reference Centre, University of Torino, 10125 Torino, Italy

Iva Dzeba - Laboratoire de Réactivité et Chimie des Solides, Université de Picardie Jules Verne (UPJV), CNRS UMR 7314, 80039 Amiens, France

Fionnuala Grifoni - Laboratoire de Réactivité et Chimie des Solides, Université de Picardie Jules Verne (UPJV), CNRS UMR 7314, 80039 Amiens, France

Yameng Ren - Laboratory of Photonics and Interfaces, Ecole Polytechnique Fédérale de Lausanne (EPFL), 1015

Lausanne, Switzerland; 이이.org/0000-0002-9362-9988

Thomas Alnasser - Laboratoire de Réactivité et Chimie des Solides, Université de Picardie Jules Verne (UPJV), CNRS UMR 7314, 80039 Amiens, France

Amalia Velardo - Dipartimento di Scienze Agrarie, Forestali e Alimentari, University of Torino, Grugliasco 10095, Italy; (1) orcid.org/0000-0002-8028-6779

Raffaele Borrelli - Dipartimento di Scienze Agrarie, Forestali e Alimentari, University of Torino, Grugliasco 10095, Italy; (1) orcid.org/0000-0002-0060-4520

Stefan Haacke - IPCMS, UMR 7504, 67034 Strasbourg, France

Shaik M. Zakeeruddin - Laboratory of Photonics and Interfaces, Ecole Polytechnique Fédérale de Lausanne (EPFL), 1015 Lausanne, Switzerland

Michael Graetzel - Laboratory of Photonics and Interfaces, Ecole Polytechnique Fédérale de Lausanne (EPFL), 1015 Lausanne, Switzerland; (1) orcid.org/0000-0002-0068-0195

Claudia Barolo - Department of Chemistry, NIS Interdepartmental and INSTM Reference Centre, University of Torino, 10125 Torino, Italy; (1) orcid.org/0000-00030627-2579

Complete contact information is available at: https://pubs.acs.org/10.1021/jacsau.1c00045

\section{Author Contributions}

W.N., V.N., Y.R., and F.G. have fabricated devices in addition to optimization and characterization. I.D. performed the psTAS experiments. T.A. carried out $\mathrm{TiO}_{2}$ nanocrystals synthesis and antireflective coating work. I.N. and S.H. designed and performed all the fs-TAS experiments. N.B. and C.B. designed the dye synthesis. A.V. and R.B. performed the DFT calculations. S.M.Z. and M.G. supervised the work of Y.R. and participated in the discussions. F.S. designed the initial concept and experiments, supervised W.N., V.N., F.G., I.D., and T.A. in their work, coordinated the projects on the NIRDSSC, and wrote the first version of the manuscript.

Notes

The authors declare no competing financial interest.

\section{ACKNOWLEDGMENTS}

W.N., I.N., I.D., S.H. and F.S. wish to thank the Agence National de la Recherche (ANR) "VISION-NIR" program under grant agreement number ANR-17-CE05-0037 for financial support. N.B., F.G., T.A., Y.R., R.B., S.M.Z., M.G., C.B., and F.S. acknowledge the "IMPRESSIVE" project which received funding from the European Union's Horizon2020 research and innovation program under grant agreement number no. 826013. S.H. acknowledges funding from the ANR 
Labex NIE (ANR-11-LABX-0058 NIE). V.N. is indebted to the French Ministry of Recherche for financial support of her Ph.D. grant. F.S. wishes to thank Dr. Matteo Bonomo (UNITO) for fruitful discussions and comments. W.N. and F.S. wish also to thank Prof. A. Di Carlo, Dr. F. Matteocci, and Dr. D. Rossi from University Tor Vegata for fruitful discussion on AVT, CRI, and CCT assessment. Mrs. Daphné Boursier (LRCS) is acknowledged for proof-reading the manuscript.

\section{REFERENCES}

(1) Electricity production from wind and solar photovoltaic power in the EU, Feb. 2018, https://eca.europa.eu/Lists/ECADocuments/ BP_WIND_SOLAR/BP_WIND_SOLAR_EN.pdf.

(2) Lunt, R. R. Theoretical limits for visibly transparent photovoltaics. Appl. Phys. Lett. 2012, 101, 043902.

(3) Yoon, J.; Baca, A. J.; Park, S. I.; Elvikis, P.; Geddes, J. B.; Li, L.; Kim, R. H.; Xiao, J.; Wang, S.; Kim, T. H.; et al. Ultrathin silicon solar microcells for semitransparent, mechanically flexible and microconcentrator module designs. Nat. Mater. 2008, 7, 907-915.

(4) Eperon, G. E.; Bryant, D.; Troughton, J.; Stranks, S. D.; Johnston, M. B.; Watson, T.; Worsley, D. A.; Snaith, H. J. Efficient, semitransparent neutral-colored solar cells based on microstructured formamidinium lead trihalide perovskite. J. Phys. Chem. Lett. 2015, 6, 129-138.

(5) Eperon, G. E.; Burkalov, V. M.; Goriely, A.; Snaith, H. J. Neutral color semi-transparent microstructured perovskite solar cells. ACS Nano 2014, 8, 591.

(6) Zhang, X.; Eperon, G. E.; Liu, J.; Johansson, E. M. J. Semitransparent quantum dot solar cell. Nano Energy 2016, 22, 70-78.

(7) Saifullah, M.; Ahn, S. J.; Gwak, J.; Ahn, S.; Kim, K.; Cho, J.; Park, J. H.; Eo, Y. J.; Cho, A.; Yoo, J. S.; et al. Development of semitransparent CIGS thin-film solar cells modified with a sulfurizedAgGa layer for building applications. J. Mater. Chem. A 2016, 4, 10542-10551.

(8) Karsthof, R.; Racke, P.; von Wenckstern, H.; Grundmann, M. Semi-transparent $\mathrm{NiO} / \mathrm{ZnO}$ UV photovoltaic cells. Phys. Status Solidi A 2016, 213, 30-27.

(9) Lim, J. W.; Lee, D. J.; Yun, S. J. Semi-transparent amorphous silicon solar cells using a thin p-Si layer and a buffer layer. ECS Solid State Lett. 2013, 2, Q47-Q49.

(10) Guo, F.; Azimi, H.; Hou, Y.; Przybilla, T.; Hu, M.; Bronnbauer, C.; Langner, S.; Spiecker, E.; Forberich, K.; Brabec, C. J. Highperformance semi-transparent perovskite solar cells with solutionprocessed silver nanowires as top electrodes. Nanoscale 2015, 7, $1642-1649$.

(11) Della Gaspera, E.; Peng, Y.; Hou, Q.; Spiccia, L.; Bach, U.; Jasieniak, J. J.; Cheng, Y.-B. Ultra-thin high efficiency semi-transparent perovskite solar cells. Nano Energy 2015, 13, 249-257.

(12) Lunt, R. R.; Bulovic, V. Transparent, near-infrared organic photovoltaic solar cells for window and energy-scavenging applications. Appl. Phys. Lett. 2011, 98, 113305.

(13) Chen, C. C.; Dou, L.; Zhu, R.; Chung, C. H.; Song, T. B.; Zheng, Y. B.; Hawks, S.; Li, G.; Weiss, P. S.; Yang, Y. Visibly transparent polymer solar cells produced by solution processing. ACS Nano 2012, 6, 7185-7190.

(14) Traverse, C. J.; Pandey, R.; Barr, M. C.; Lunt, R. R. Emergence of highly transparent photovoltaics for distributed applications. Nat. Energy 2017, 2, 849-860.

(15) Davy, N. C.; Sezen-Edmonds, M.; Gao, J.; Lin, X.; Liu, A.; Yao, N.; Kahn, A.; Loo, Y. L. Pairing of near-ultraviolet solar cells with electrochromic windows for smart management of the solar spectrum. Nat. Energy 2017, 2, 17104.

(16) Xue, Q.; Xia, R.; Brabec, C. J.; Yip, H. L. Recent advances in semi-transparent polymer and perovskite solar cells for power generating window applications. Energy Environ. Sci. 2018, 11, 1688.

(17) Zhao, Y.; Meek, G. A.; Levine, B. G.; Lunt, R. R. Near-infrared harvesting transparent luminescent solar concentrators. Adv. Opt. Mater. 2014, 2, 606-611.
(18) Nazeeruddin, Md. K.; Pechy, P.; Renouard, T.; Zakeeruddin, S. M.; Humphry-Baker, R.; Comte, P.; Liska, P.; Cevey, L.; Costa, E.; Shklover, V.; et al. Engineering of efficient panchromatic sensitizers for nanocrystalline $\mathrm{TiO}_{2}$-based solar cells. J. Am. Chem. Soc. 2001, 123, 1613-1624.

(19) Yella, A.; Lee, H. W.; Tsao, H. N.; Yi, C.; Chandiran, A. K.; Nazeeruddin, Md. K.; Diau, E. W. G.; Yeh, C. Y.; Zakeeruddin, S. M.; Graetzel, M. Porphyrin-sensitized solar cells with cobalt (II/III)-based redox electrolyte exceed 12\% efficiency. Science 2011, 334, 629-634.

(20) Kakiage, K.; Aoyama, Y.; Yano, T.; Oya, K.; Fujisawa, J. I.; Hanaya, M. Highly-efficient dye-sensitized solar cells with collaborative sensitization by silyl-anchor and carboxy-anchor dyes. Chem. Commun. 2015, 51, 15894-15897.

(21) Holliman, P. J.; Mohsen, M.; Connell, A.; Davies, M. L.; AlSalihi, K.; Pitak, M. B.; Tizzard, G. J.; Coles, S. J.; Harrington, R. W.; Clegg, W.; et al. Ultra-fast co-sensitization and tri-sensitization of dyesensitized solar cells with N719, SQ1 and triarylamine dyes. J. Mater. Chem. 2012, 22, 13318-13327.

(22) Yum, J.-H.; Jang, S. R.; Walter, P.; Geiger, T.; Nüesch, F.; Kim, S.; Ko, J.; Grätzel, M.; Nazeeruddin, Md. K. Efficient co-sensitization of nanocrystalline $\mathrm{TiO}_{2}$ films by organic sensitizers. Chem. Commun. 2007, 44, 4680-4682.

(23) Shiu, J.-W.; Chang, Y.-C.; Chan, C.-Y.; Wu, H.-P.; Hsu, H.-Y.; Wang, C.-L.; Lin, C.-Y.; Diau, E. W. G. Panchromatic co-sensitization of porphyrin-sensitized solar cells to harvest near-infrared light beyond $900 \mathrm{~nm}$. J. Mater. Chem. A 2015, 3, 1417-1420.

(24) Islam, A.; Akhtaruzzaman, M.; Chowdhury, T. H.; Qin, C.; Han, L.; Bedja, I. M.; Stalder, R.; Schanze, K. S.; Reynolds, J. R. Enhanced photovoltaic performances of dye-sensitized solar cells by co-sensitization of benzothiadiazole and squaraine-based dyes. ACS Appl. Mater. Interfaces 2016, 8, 4616-4623.

(25) Ogura, R. Y.; Nakane, S.; Morooka, M.; Orihashi, M.; Suzuki, Y.; Noda, K. High-performance dye-sensitized solar cell with a multiple dye system. Appl. Phys. Lett. 2009, 94, 073308.

(26) Qin, C. J.; Numata, Y.; Zhang, S. F.; Islam, A.; Yang, X. D.; Sodeyama, K.; Tateyama, Y.; Han, L. Y. A Near-Infrared cisconfigured squaraine co-sensitizer for high efficiency dye-sensitized solar cells. Adv. Funct. Mater. 2013, 23, 3782-3789.

(27) Chang, S.; Wang, H.; Lin Lee, L. T.; Zheng, S.; Li, Q.; Wong, K. Y.; Wong, W.-K.; Zhu, X.; Wong, W.-Y.; Xiao, X.; Chen, T. Panchromatic light harvesting by N719 with a porphyrin molecule for high-performance dye-sensitized solar cells. J. Mater. Chem. C 2014, 2, $3521-3526$

(28) Dong, L. H.; Zheng, Z. W.; Wang, Y. F.; Li, X.; Hua, J. L.; Hu, A. G. Co-sensitization of N719 with polyphenylenes from the Bergman cyclization of maleimide-based enediynes for dye-sensitized solar cells. J. Mater. Chem. A 2015, 3, 11607-11614.

(29) Zhang, K.; Qin, C.; Yang, X.; Islam, A.; Zhang, S.; Chen, H.; Han, L. High performance, transparent, dye-sensitized solar cells for see-through photovoltaic windows. Adv. Energy. Mater. 2014, 4, 1301966.

(30) Huaulmé, Q.; Mwalukuku, V. M.; Joly, D.; Liotier, J.; Kervella, Y.; Maldivi, P.; Narbey, S.; Oswald, F.; Riquelme, A. J.; Anta, J. A.; Demadrille, R. Photochromic dye-sensitized solar cells with lightdriven adjustable optical transmission and power conversion efficiency. Nat. Energy 2020, 5, 468-477.

(31) Roy, A.; Ghosh, A.; Bhandari, S.; Selvaraj, P.; Sundaram, S.; Mallick, T. K. Color comfort evaluation of dye-sensitized solar cell (DSSC) based Building-Integrated Photovoltaic (BIPV) glazing after 2 years of ambient exposure. J. Phys. Chem. C 2019, 123, 2383423837.

(32) Ghosh, A.; Selvaraj, P.; Sundaram, S.; Mallick, T. K. The colour rendering index and correlated colour temperature of dye-sensitized solar cell for adaptive glazing application. Sol. Energy 2018, 163, 53744.

(33) Zhao, W.; Jun Hou, Y.; Song Wang, X.; Wen Zhang, B.; Cao, Y.; Yang, R.; Bo Wang, W.; Rui Xiao, X. Study on squarylium cyanine dyes for photoelectric conversion. Sol. Energy Mater. Sol. Cells 1999, 58, 173-183. 
(34) Alex, S.; Santhosh, U.; Das, S. Dye sensitization of nanocrystalline $\mathrm{TiO}_{2}$ : enhanced efficiency of unsymmetrical versus symmetrical squaraine dyes. J. Photochem. Photobiol., A 2005, 172, $63-71$.

(35) Yum, J.-H.; Walter, P.; Huber, S.; Rentsch, D.; Geiger, T.; Nuesch, F.; De Angelis, F.; Gratzel, M.; Nazeeruddin, M. K. Efficient far red sensitization of nanocrystalline $\mathrm{TiO}_{2}$ films by an unsymmetrical squaraine dye. J. Am. Chem. Soc. 2007, 129, 10320-10321.

(36) Geiger, T.; Kuster, S.; Yum, J.-H.; Moon, S.-J.; Nazeeruddin, M. K.; Gratzel, M.; Nuesch, F. Molecular design of unsymmetrical squaraine dyes for high efficiency conversion of low energy photons into electrons using $\mathrm{TiO}_{2}$ nanocrystalline films. Adv. Funct. Mater. 2009, 19, 2720-2727.

(37) Park, J.; Barolo, C.; Sauvage, F.; Barbero, N.; Benzi, C.; Quagliotto, P.; Coluccia, S.; Di, Censo D.; Grätzel, M.; Nazeeruddin, Md. K.; Viscardi, G. Symmetric vs. asymmetric squaraines as photosensitisers in mesoscopic injection solar cells: a structureproperty relationship study. Chem. Commun. 2012, 48, 2782-2784.

(38) Kuster, S.; Sauvage, F.; Nazeeruddin, Md. K.; Graetzel, M.; Nuesch, F.; Geiger, T. Unsymmetrical squaraine dimer with an extended $\pi$-electron framework: An approach in harvesting near infrared photons for energy conversion. Dyes Pigm. 2010, 87, 30-38.

(39) Magistris, C.; Martiniani, S.; Barbero, N.; Park, J.; Benzi, C.; Anderson, A.; Law, C.; Barolo, C.; O’Regan, B. Near-infrared absorbing squaraine dye with extended $\pi$ conjugation for dyesensitized solar cells. Renewable Energy 2013, 60, 672-678.

(40) Maeda, T.; Arikawa, S.; Nakao, H.; Yagi, S.; Nakazumi, H. Linearly $\pi$-extended squaraine dyes enable the spectral response of dye-sensitized solar cells in the NIR region over $800 \mathrm{~nm}$. New J. Chem. 2013, 37, 701-708

(41) Maeda, T.; Hamamura, Y.; Miyanaga, K.; Shima, N.; Yagi, S.; Nakazumi, H. Near-infrared absorbing squarylium dyes with linearly extended $\pi$-conjugated structure for dye-sensitized solar cell applications. Org. Lett. 2011, 13, 5994-5997.

(42) Park, J.; Barbero, N.; Yoon, J.; Dell'Orto, E.; Galliano, S.; Borrelli, R.; Yum, J.-H.; Di Censo, D.; Gratzel, M.; Nazeeruddin, M. K.; Barolo, C.; Viscardi, G. Panchromatic symmetrical squaraines: a step forward in the molecular engineering of low cost blue-greenish sensitizers for dye-sensitized solar cells. Phys. Chem. Chem. Phys. 2014, 16, 24173-24177.

(43) Pandey, S. S.; Inoue, T.; Fujikawa, N.; Yamaguchi, Y.; Hayase, $S$. Substituent effect in direct ring functionalized squaraine dyes on near infra-red sensitization of nanocrystalline $\mathrm{TiO}_{2}$ for molecular photovoltaics. Thin Solid Films 2010, 519, 1066-1073.

(44) Qin, C.; Numata, Y.; Zhang, S.; Yang, X.; Islam, A.; Zhang, K.; Chen, H.; Han, L. Novel near-infrared squaraine sensitizers for stable and efficient dye-sensitized solar cells. Adv. Funct. Mater. 2014, 24, 3059-3066.

(45) Novelli, V.; Barbero, N.; Barolo, C.; Viscardi, G.; Sliwa, M.; Sauvage, F. Electrolyte containing lithium cation in squarainesensitized solar cells: interactions and consequences for performance and charge transfer dynamics. Phys. Chem. Chem. Phys. 2017, 19, 27670-27681.

(46) Tian, M.; Tatsuura, S.; Furuki, M.; Sato, Y.; Iwasa, I.; Pu, L. S. Discovery of novel dyes with absorption maxima at $1.1 \mu \mathrm{m}$. J. Am. Chem. Soc. 2003, 125, 348-349.

(47) Keil, D.; Hartmann, H.; Reichardt, C. Synthesis and spectroscopic characterization of new NIR absorbing (2-thienyl) and (4-dialkylaminoaryl)-substituted croconic acid dyes. Liebigs Ann. Chem. 1993, 9, 935-939.

(48) Ehret, A.; Stuhl, L.; Spitler, M. T. Spectral sensitization of $\mathrm{TiO}_{2}$ nanocrystalline electrodes with aggregated cyanine dyes. J. Phys. Chem. B 2001, 105, 9960-9965.

(49) Sayama, K.; Tsukagoshi, S.; Mori, T.; Hara, K.; Ohga, Y.; Shinpou, A.; Abe, Y.; Suga, S.; Arakawa, H. Efficient sensitization of nanocrystalline $\mathrm{TiO}_{2}$ films with cyanine and merocyanine organic dyes. Sol. Energy Mater. Sol. Cells 2003, 80, 47-71.
(50) Ono, T.; Yamaguchi, T.; Arakawa, H. Study on dye-sensitized solar cell using novel infrared dye. Sol. Energy Mater. Sol. Cells 2009, 93, 831-835.

(51) Funabiki, K.; Mase, H.; Hibino, A.; Tanaka, N.; Mizuhata, N.; Sakuragi, Y.; Nakashima, A.; Yoshida, T.; Kubota, Y.; Matsui, M. Synthesis of a novel heptamethine-cyanine dye for use in near-infrared active dye-sensitized solar cells with porous zinc oxide prepared at low temperature. Energy Environ. Sci. 2011, 4, 2186.

(52) Geiger, T.; Schoger, I.; Rentsch, D.; Veron, A. C.; Oswald, F.; Meyer, T.; Nuesch, F. Unsymmetrical heptamethine dyes for NIR dye-sensitized solar cells. Int. J. Photoenergy 2014, 258984.

(53) Galliano, S.; Novelli, V.; Barbero, N.; Smarra, A.; Viscardi, G.; Borrelli, R.; Sauvage, F.; Barolo, C. Dicyanovinyl and cyano-ester benzoindolenine squaraine dyes: The effect of the central functionalization on dye-sensitized solar cell performance. Energies 2016, 9, 486.

(54) Encinas, C.; Otazo, E.; Rivera, L.; Miltsov, S.; Alonso, J. Croconines: new acidochromic dyes for the near infrared region. Tetrahedron Lett. 2002, 43, 8391-8393.

(55) Li, Z.; Jin, Z.; Kasatani, K.; Okamoto, H. Resonant third-order optical nonlinearities of 1, 3-bis [(3, 3-dimethylindolin-2-ylidene) methyl] croconine. Phys. B 2006, 382, 229-234.

(56) Ciubini, B.; Visentin, S.; Serpe, L.; Canaparo, R.; Fin, A.; Barbero, N. Design and synthesis of symmetrical pentamethine cyanine dyes as NIR photosensitizers for PDT. Dyes Pigm. 2019, 160, 806-813.

(57) Hagberg, D. P.; Yum, J.-H.; Lee, H.; De Angelis, F.; Marinado, T.; Karlsson, K. M.; Humphry-Baker, R.; Sun, L.; Hagfeldt, A.; Gratzel, M.; Nazeeruddin, M.. K. Molecular engineering of organic sensitizers for dye-sensitized solar cell applications. J. Am. Chem. Soc. 2008, 130, 6259-6266.

(58) Grätzel, M. Photoelectrochemical cells. Nature 2001, 414, $338-344$

(59) Nazeeruddin, Md. K.; Zakeeruddin, S. M.; Humphry-Baker, R.; Jirousek, M.; Liska, P.; Vlachopoulos, N.; Shklover, V.; Fischer, C.-H.; Grätzel, M. Acid-base equilibria of (2,2'-bipyridyl-4,4'-dicarboxylic acid) ruthenium(II) complexes and the effect of protonation on charge-transfer sensitization of nanocrystalline titania. Inorg. Chem. 1999, 38, 6298-6305.

(60) Hagfeldt, A.; Grätzel, M. Molecular photovoltaics. Acc. Chem. Res. 2000, 33, 269-277.

(61) Paternò, G. M.; Barbero, N.; Galliano, S.; Barolo, C.; Lanzani, G.; Scotognella, F.; Borrelli, R. Excited state photophysics of squaraine dyes for photovoltaic applications: an alternative deactivation scenario. J. Mater. Chem. C 2018, 6, 2778-2785.

(62) Kay, A.; Graetzel, M. Artificial photosynthesis. 1. Photosensitization of titania solar cells with chlorophyll derivatives and related natural porphyrins. J. Phys. Chem. 1993, 97, 6272-6277.

(63) Salvatori, P.; Marotta, G.; Cinti, A.; Anselmi, C.; Mosconi, E.; De Angelis, F. Supramolecular interactions of chenodeoxycholic acid increase the efficiency of dye-sensitized solar cells based on a cobalt electrolyte. J. Phys. Chem. C 2013, 117, 3874-3887.

(64) Zhang, L.; Cole, J. Dye aggregation in dye-sensitized solar cells. J. Mater. Chem. A 2017, 5, 19541-19559.

(65) Chandiran, A. K.; Zakeeruddin, S. M.; Humphry-Baker, R.; Nazeeruddin, Md. K.; Grätzel, M.; Sauvage, F. Investigation on the interface modification of $\mathrm{TiO}_{2}$ surfaces by functional co-adsorbents for high-efficiency dye-sensitized solar cells. ChemPhysChem 2017, 18, 2724-2731.

(66) Kroeze, J.; Hirata, N.; Koops, S.; Nazeeruddin, Md.K.; Schmidt-Mende, L.; Grätzel, M.; Durrant, J. Alkyl chain barriers for kinetic optimization in dye-sensitized solar cells. J. Am. Chem. Soc. 2006, 128, 16376-16383.

(67) Katoh, R.; Kasuya, M.; Kodate, S.; Furube, A.; Fuke, N.; Koide, $\mathrm{N}$. Effects of 4-tert-butylpyridine and Li-ions on photoinduced electron injection efficiency in black dye-sensitized nanocrystalline $\mathrm{TiO}_{2}$ films. J. Phys. Chem. C 2009, 113, 20738-20744. 
(68) Koops, S. E.; O’Regan, B.; Barnes, P. R. F.; Durrant, J. R. Parameters influencing the efficiency of electron injection in dyesensitized solar cells. J. Am. Chem. Soc. 2009, 131, 4808-4818.

(69) Boschloo, G.; Haggman, L.; Hagfeldt, A. Quantification of the effect of 4-tert-butylpyridine addition to $\mathrm{I}^{-} / \mathrm{I}_{3}{ }^{-}$redox electrolytes in dye-sensitized nanostructured $\mathrm{TiO}_{2}$ solar cells. J. Phys. Chem. B 2006, 110, 13144-13150.

(70) Katoh, R.; Fuke, N.; Furube, A.; Koide, N. Effect of dye coverage on photo-induced electron injection efficiency in N719sensitized nanocrystalline $\mathrm{TiO}_{2}$ films. Chem. Phys. Lett. 2010, 489, 202-206.

(71) Kelly, C. A.; Farzad, F.; Thompson, D. W.; Stipkala, J. M.; Meyer, G. J. Cation-controlled interfacial charge injection in sensitized nanocrystalline $\mathrm{TiO}_{2}$. Langmuir 1999, 15, 7047-7054.

(72) Park, N.-G.; Chang, S.-H.; van de Lagemaat, J.; Kimand, K.-J.; Frank, A. J. Effect of cations on the open-circuit photovoltage and the charge injection efficiency of dye-sensitized nanocrystalline rutile $\mathrm{TiO}_{2}$ films. Bull. Korean Chem. Soc. 2000, 21, 985-988.

(73) Sauvage, F.; Decoppet, J.-D.; Zhang, M.; Zakeeruddin, S. M.; Comte, P.; Nazeeruddin, Md. K.; Wang, P.; Grätzel, M. Effect of sensitizer adsorption temperature on the performance of dyesensitized solar cells. J. Am. Chem. Soc. 2011, 133, 9304-9310.

(74) Feldt, S. M.; Gibson, E. A.; Gabrielsson, E.; Sun, L.; Boschloo, G.; Hagfeldt, A. Design of organic dyes and cobalt polypyridine redox mediators for high-efficiency dye-sensitized solar cells. J. Am. Chem. Soc. 2010, 132, 16714-16724.

(75) Yella, A.; Lee, H.-W.; Tsao, H. N.; Yi, C.; Chandiran, A. K.; Nazeeruddin, Md. K.; Diau, E.W.-G.; Yeh, C.-Y.; Zakeeruddin, S. M.; Grätzel, M. Porphyrin-sensitized solar cells with cobalt (II/III)-based redox electrolyte exceed 12\% efficiency. Science 2011, 334, 629-634.

(76) Yum, J.-H.; Baranoff, E.; Kessler, F.; Moehl, T.; Ahmad, S.; Bessho, T.; Marchioro, A.; Ghadiri, E.; Moser, J.-E.; Yi, C.; Nazeeruddin, Md. K.; Graetzel, M. A cobalt complex redox shuttle for dye-sensitized solar cells with high open-circuit potentials. Nat. Commun. 2012, 3, 631.

(77) Mosconi, E.; Yum, J.-H.; Kessler, F.; Gomez Garcia, C. J.; Zuccaccia, C.; Cinti, A.; Nazeeruddin, M. K.; Gratzel, M.; De Angelis, F. Cobalt electrolyte/dye interactions in dye-sensitized solar cells: a combined computational and experimental study. J. Am. Chem. Soc. 2012, 134, 19438-19453.

(78) Mathew, S.; Yella, A.; Gao, P.; Humphry-Baker, R.; Curchod, B. F. E.; Ashari-Astani, N.; Tavernelli, I.; Rothlisberger, U.; Nazeeruddin, Md. K.; Gratzel, M. Dye-sensitized solar cells with $13 \%$ efficiency achieved through the molecular engineering of porphyrin sensitizers. Nat. Chem. 2014, 6, 242-247.

(79) Yao, Z.; Wu, H.; Li, Y.; Wang, J.; Zhang, J.; Zhang, M.; Guo, Y.; Wang, P. Dithienopicenocarbazole as the kernel module of lowenergy-gap organic dyes for efficient conversion of sunlight to electricity. Energy Environ. Sci. 2015, 8, 3192.

(80) Ren, Y.; Sun, D.; Cao, Y.; Tsao, H. N.; Yuan, Y.; Zakeeruddin, S. M.; Wang, P.; Grätzel, M. A stable blue photosensitizer for color palette of dye-sensitized solar cells reaching $12.6 \%$ efficiency. J. Am. Chem. Soc. 2018, 140, 2405-2408.

(81) Gregg, B. A.; Pichot, F.; Ferrere, S.; Fields, C. L. Interfacial recombination processes in dye-sensitized solar cells and methods to passivate the interfaces. J. Phys. Chem. B 2001, 105, 1422-1429.

(82) Klahr, B. M.; Hamann, T. W. Performance enhancement and limitations of cobalt bipyridyl redox shuttles in dye-sensitized solar cells. J. Phys. Chem. C 2009, 113, 14040-14045.

(83) Feldt, S. M.; Cappel, U. B.; Johansson, E. M. J.; Boschloo, G.; Hagfeldt, A. Characterization of surface passivation by poly(methylsiloxane) for dye-sensitized solar cells employing the ferrocene redox couple. J. Phys. Chem. C 2010, 114, 10551-10558.

(84) Nelson, J. J.; Amick, T. J.; Elliott, C. M. Mass transport of polypyridyl cobalt complexes in dye-sensitized solar cells with mesoporous $\mathrm{TiO}_{2}$ photoanodes. J. Phys. Chem. C 2008, 112, 18255-18263.

(85) Antila, L. J.; Heikkila, M. J.; Aumanen, V.; Kemell, M.; Myllyperkio, P.; Leskela, M.; Korppi-Tommola, J. E. I. Suppression of forward electron injection from $\mathrm{Ru}(\mathrm{dcbpy})_{2}(\mathrm{NCS})_{2}$ to nanocrystalline $\mathrm{TiO}_{2}$ film as a result of an interfacial $\mathrm{Al}_{2} \mathrm{O}_{3}$ barrier layer prepared with Atomic Layer Deposition. J. Phys. Chem. Lett. 2010, 1, 536.

(86) Chandiran, A. K.; Tetreault, N.; Humphry-Baker, R.; Kessler, F.; Baranoff, E.; Yi, C.; Nazeeruddin, Md. K.; Gratzel, M. Subnanometer $\mathrm{Ga}_{2} \mathrm{O}_{3}$ tunnelling layer by atomic layer deposition to achieve $1.1 \mathrm{~V}$ open-circuit potential in dye-sensitized solar cells. Nano Lett. 2012, 12, 3941-3947.

(87) Finlayson, E. U., Arasteh, D. K., Huizenga, C., Rubin, M. D., Reilly, M. S. WINDOW 4.0: Documentation of calculation procedures report no. LBL-33943; Lawrence Berkeley Laboratory and Enermodal Engineering, Inc., 1993.

(88) Fisette, P. Windows: Understanding energy efficient performance; University of Massachusetts, 2003; https://bct.eco.umass.edu/ publications/articles/windows-understanding-energy-efficientperformance/ (accessed on 01/18/2021).

(89) Williams, M. P. A.; Ethirajan, M.; Ohkubo, K.; Chen, P.; Pera, P.; Morgan, J.; White, W. H.; Shibata, M.; Fukuzumi, S.; Kadish, K. M.; Pandey, R. K. Synthesis, Photophysical, electrochemical, tumorImaging, and phototherapeutic properties of purpurinimide-Nsubstituted cyanine dyes joined with variable lengths of linkers. Bioconjugate Chem. 2011, 22, 2283-2295.

(90) Sauvage, F.; Chhor, S.; Marchioro, A.; Moser, J. E.; Graetzel, M. Butyronitrile-based electrolyte for dye-sensitized solar cells. J. Am. Chem. Soc. 2011, 133, 13103-13109.

(91) Anderson, A. Y.; Barnes, P. R. F.; Durrant, J. R.; O’Regan, B. Quantifying regeneration in dye-sensitized solar cells. J. Phys. Chem. C 2011, 115, 2439-2447.

(92) Flasque, M.; Nhien, A. N. V.; Moia, D.; Barnes, P. R. F.; Sauvage, F. Consequences of solid electrolyte interphase (SEI) Formation upon aging on charge-transfer processes in dye-sensitized solar cells. J. Phys. Chem. C 2016, 120, 18991-18998.

(93) Feldt, S. M.; Lohse, P. W.; Kessler, F.; Nazeeruddin, Md. K.; Grätzel, M.; Boschloo, G.; Hagfeldt, A. Regeneration and recombination kinetics in cobalt polypyridine based dye-sensitized solar cells, explained using Marcus theory. Phys. Chem. Chem. Phys. 2013, 15, 7087.

(94) Pydzińska, K.; Ziółek, M. Solar cells sensitized with nearinfrared absorbing dye: Problems with sunlight conversion efficiency revealed in ultrafast laser spectroscopy studies. Dyes Pigm. 2015, 122, $272-279$.

(95) Sinibaldi, A.; Fieramosca, A.; Rizzo, R.; Anopchenko, A.; Danz, N.; Munzert, P.; Magistris, C.; Barolo, C.; Michelotti, F. Combining label-free and fluorescence operation of Bloch surface wave optical sensors. Opt. Lett. 2014, 39, 2947-2950.

(96) Park, J.; Barbero, N.; Yoon, J.; Dell'Orto, E.; Galliano, S.; Borrelli, R.; Yum, J.-H.; Di Censo, D.; Gratzel, M.; Nazeeruddin, M.. K.; Barolo, C.; Viscardi, G. Panchromatic symmetrical squaraines: a step forward in the molecular engineering of low cost bluegreenish sensitizers for dye-sensitized solar cells. Phys. Chem. Chem. Phys. 2014, 16, 24173-24177.

(97) Barbero, N.; Magistris, C.; Park, J.; Saccone, D.; Quagliotto, P.; Buscaino, R.; Medana, C.; Barolo, C.; Viscardi, G. Microwave-assisted synthesis of near-infrared fluorescent indole-based squaraines. Org. Lett. 2015, 17, 3306-3309.

(98) Ito, S.; Murakami, T. N.; Comte, P.; Liska, P.; Grätzel, C.; Nazeeruddin, Md. K.; Grätzel, M. Fabrication of thin film dye sensitized solar cells with solar to electric power conversion efficiency over 10\%. Thin Solid Films 2008, 516, 4613.

(99) McCamy, C. S. Correlated color temperature as an explicit function of chromaticity coordinates. Color Res. Appl. 1992, 17, 142144.

(100) Commission Internationale de l'Eclairage. CIE 1988, $2^{\circ}$ spectral luminous efficiency function for photopic vision, CIE 086-1990; 1990.

(101) Liu, L.; Eisenbrandt, P.; Roland, T.; Polkehn, M.; Schwartz, P. O.; Bruchlos, K.; Omiecienski, B.; Ludwigs, S.; Leclerc, N.; Zaborova, E.; Léonard, J.; Méry, S.; Burghardt, I.; Haacke, S. Controlling charge 
separation and recombination by chemical design in donor-acceptor dyads. Phys. Chem. Chem. Phys. 2016, 18, 18536.

(102) Roland, T.; Leonard, J.; Hernandez Ramirez, G.; Mery, S.; Yurchenko, O.; Ludwigs, S.; Haacke, S. Sub-100 fs charge transfer in a novel donor-acceptor-donor triad organized in a smectic film. Phys. Chem. Chem. Phys. 2012, 14, 273-279.

(103) Snellenburg, J. J.; Laptenok, S. P.; Seger, R.; Mullen, K. M.; Stokkum, I. H. M. v. Glotaran : A Java-Based Graphical User Interface for the R Package TIMP. J. Stat. Soft. 2012, 49, 1-22. http://www. jstatsoft.org/. 